\title{
TEXTKRITISCHE ÜBERLEGUNGEN ZUM CORPUS DER SENECA-TRAGÖDIEN
}

\author{
Thomas Gärtner
}

\section{Zusammenfassung}

Kritisch-exegetische Überlegungen auf der Grundlage des aktuellen Forschungsstands zu folgenden Partien aus dem Corpus der Seneca Tragödien: Herc. 19-21; 21-26; 104-109; 116-122; 1179-1182; 1194-1198; 1229-1236; 1336-1341; Tro. 22-27; 51-56; 59-62; 178-181; 301-305; 365-370; 412-415; 757-759; 799-806; 917-924; 981-998; 1152-1154; Phoen. 22-26; 173-176; 354-362; 434-442; 480-483; Med. 134-136; 447-453; 465-476; 515-519; 777 f.; 954-957; Phaed. 687-693; 1207-1210; Oed. 233-238; 384-389; 957-962; 1014-1018; 1024-1031; Ag. 193-202; 207-219; 544-556; 659-663; 1001-1003; Thy. 13-20; 40-48; 56-62; 267-275; 10961102; HO 207-218; 380-390; 719-721; 860-862; 900-902; 929-931; 948-958; 1245-1247; 1456-1466; 15181527; 1607-1617; Oct. 45-50; 100 f.; 498-502; 636-643; 717-723; 952-957; 963-968.

Die folgenden textkritischen Überlegungen zum Corpus der Seneca-Tragödien verstehen sich als ein bescheidener Versuch, alternative Lösungsvorschläge zu einigen problematischen Partien zu bieten. Sie beziehen sich auf das monumentale Fundament zu den Seneca-Tragödien, welches durch die Arbeiten von Otto Zwierlein gelegt wurde, vor allem durch seine kritische Oxford-Ausgabe, seinen Kritischen Kommentar (Wiesbaden 1986, im folgenden KK) und seine weiteren Einzelbeobachtungen, die jetzt im ersten Band seiner Lucubrationes Philologae (Berlin 2004, im folgenden LP I) in gesammelter und aktualisierter Form vorliegen. Ein weiteres wichtiges Hilfsmittel, welches die textkritische Arbeit wesentlich erleichtert, ist das Repertorium der Konjekturen in den Seneca-Tragödien von Margarethe Billerbeck und Mario Somazzi (Mnem. Suppl.316, Leiden 2009), welches es dank seiner detaillierten Bibliographie ermöglicht, auf bibliographische Hinweise zu Fundstellen weitestgehend zu verzichten. An neuerer Literatur habe ich lediglich den bei Billerbeck noch nicht berücksichtigten zweiten Band der neuen italienischen Ausgabe von Giardina (Pisa \& Rom 2007 und 2009) herangezogen.

Herc. 19-21

$$
\text { ... una me dira ac fera }
$$

20 Thebana tellus matribus sparsa impiis

Quotiens novercam fecit! ...

Axelson (bei Zwierlein KK 15 f.) änderte das überlieferte nuribus (dessen metrische Unmöglichkeit die Früheren nicht überzeugend zu heilen wußten) in matribus und verstand den Ausdruck matribus sparsa impiis in dem nicht ganz leichten Sinne a matribus impiis cruore Penthei sparsa. Diese Schwierigkeit hat man mehrfach gegen Axelsons Konjektur ins Feld geführt; hinzuzunehmen wäre noch, daß sich impiis in seinem Vollsinn "frevelhaft" ausschließlich auf Agaue bezieht und sonderbar neben dem - an sich in diesem mythologischen Zusammenhang wohlbelegten (vgl. Zwierlein LP I 315 f.) ungenauen Plural matribus steht. In Oed. 436 f. ist das Adjektiv impia degegen gerade auf Agaue selbst, nicht auf die übrigen Mütter bezogen: Tunc Cadmeas inter matres/ Impia maenas/ ... 
Fitch hat zunächst im Kommentar alternativ sparsa in aspersa geändert (unterstützt von Hudson-Williams) und damit eine Verwendung des Kompositums aspergere vorausgesetzt, die sprachlich dubios ist (vgl. Zwierlein LP I 315 f.) und zudem durch die Parallelen $444 \mathrm{f}$. post Phlegram impio/ Sparsam cruore und 1217 Cruore corpus impio sparsum widerraten wird. Sachlich versteht er nuribus aspersa impiis in dem Sinne, "that Jupiter's women are scattered throughout Thebens", wogegen Zwierlein LP I $315 \mathrm{f}$. richtig anführt, daß die Geliebten des Jupiter allesamt dem thebanischen Königshaus entstammten.

Dagegen in Annaeana (2004a: 5 f.) schließt sich Fitch Axelsons Konjektur an, interpretiert den von diesem konstituierten Text aber in dem Sinne "scattered with ungodly mothers" und bezieht dies auf die Nebenbuhlerinnen der Juno (hiergegen Zwierlein LP I 335 Anm. 5).

Watt hebt seinerseits wiederum die Schwierigkeit der Ellipse von cruore in Axelsons Konjektur hervor, ändert nuribus in caedibus (Giardina konjiziert unmetrisches necibus) und bezieht dies allgemein auf thebanische Frevel.

Im unmittelbaren Anschluß an dira ac feral Thebana tellus scheint in der Tat eine allgemeine diskriminierende Qualifikation des mythischen Thebens wünschenswert; zu den Nebenbuhlerinnen Junos fügt sich als Eigenschaft Thebens weder „befleckt” noch "durchsetzt" in überzeugender Weise. Eine solche stereotype mythologische Diskriminierung erfolgt aber üblicherweise eher durch den Brudermord von Eteocles und Polynices als durch die Tat der Agaue (vgl. auch die ähnliche Diskriminierung von Agamemnons Heimatstadt Argos im Munde des Pyrrhus in 339 scelere quae fratrum caret; umgekehrt heißt es über Sparta in Phoen. 128 Spartenque fratre nobilem gemino; Thy. $627 \mathrm{f}$. Argos et Sparte, pios / Sortita fratres ). Schreibt man nun in Variation von Axelsons Konjektur fratribus sparsa impiis, so vermindern sich die Schwierigkeiten der Ellipse von cruore, insofern man fratribus ... impiis leicht als den Theben befleckenden „Brüderfrevel” versteht (einer vergleichsweise einfachen Interpretation als „Mütterfrevel” entzieht sich das pluralische matribus ... impiis); die Vorstellung „blutbefleckt” kommt höchstens indirekt hinzu, insofern man zunächst an das gottlose Wüten des Brüderpaars (und vielleicht auch seine Abstammung von Oedipus) denken wird. Zu solcher sinistrer Hineinziehung des Oedipus-Mythos in den Hercules vgl. die Verwünschungen der Megara in 387-389 (quid geminum nefas/ Mixtumque nomen coniugis gnati patris?/ Quid bina fratrum castra? Quid totidem rogos?) und 496 (Et nuptiales impii Oedipodae faces). Ferner könnte der Ausdruck fratribus sparsa impiis auch auf den Sparten-Mythos bezogen werden (vgl. Oed. 588 Fratrum catervae dente Dircaeo satae, ferner 749 f.).

Herc. $21-26$

... escendat licet

Meumque uictrix teneat Alcmene locum,

Pariterque natus astra promissa occupet,

In cuius ortus mundus impendit diem

25 Tardusque Eoo Phoebus effulsit mari

Retinere mersum iussus Oceano iubar?

Wenn die Worte mundus impendit diem bedeuten sollten "die Welt wandte einen Tag auf” (vgl. Billerbecks Übersetzung "die Welt gab einen Tag hinzu”), so müßte diem 
ein quantifizierendes Attribut (unum oder allenfalls totum) bei sich haben, wie die bei Fitch z.St. angeführten Parallelen (besonders HO 1697 f. und 1865 f.) zeigen. Besser paßt indes zur Fortführung (Tardusque ... Phoebus und Retinere ... iussus), der Gedanke, daß der Tagesanbruch verhindert wurde: In cuius ortus mundus impediit diem (dies i.q. "Tagesablauf" auch Med. 768 Die relicto Phoebus in medio stetit; Ag. 908 Stat ecce Titan dubius emerito die; Thy. $791 \mathrm{f}$. quo vertis iter/ Medioque diem perdis Olympo?). Zur metrischen Form der Versklausel vgl. Phaed. 135 subiit iugum; die Form impediit begegnet bei Ov. met. 12.392. Die Lesart impediit findet sich, worauf der anonyme Rezensent der SHT hinweist, bereits in recc. und wurde von Raphelengius nicht auf die Empfängnis, sondern auf die Geburt des Hercules bezogen.

Dann ergibt sich in dem Ausdruck In cuius ortus mundus impediit diem die besondere Pointe, daß das für die Zeugung des Hercules verwendete Substantiv ortus dasjenige Wort ist, welches eigentlich statt diem zu erwarten wäre. Durch diese austauschende Entfremdung des üblichen Ausdrucks (etwa in cuius genituram mundus impediit solis ortum) wird die Paradoxie des Geschehens aus der Sicht der Hercules-Hasserin Juno besonders herausgestellt.

Herc. 104-109

Hoc agite, poenas petite violatae Stygis;

105 Concutite pectus, acrior mentem excoquat

Quam qui caminis ignis Aetnaeis furit.

Ut possit animum captus Alcides agi,

Magno furore percitus, nobis (recc. : vobis codd.) prius

Insaniendum est: Iuno, cur nondum furis?

Das absolut gebrauchte agi befremdet ebenso wie das animum captus unnötigerweise verdoppelnde zweite auf Hercules bezügliche Partizip percitus. Dagegen erhält man eine vollkommene stilistische Entsprechung zwischen dem Wahnsinn des Hercules und demjenigen der Juno (jeweils durch ein Partizip präpariert) und zudem einen mit der Penthemimeres kongruierenden syntaktischen Einschnitt, wenn man mit veränderter Interpunktion liest:

Ut possit animum captus Alcides agi

Magno furore, percitis nobis prius

Insaniendum est: Iuno, cur nondum furis?

percitis nobis prius wird aufgegriffen durch $110 \mathrm{f}$. Me me, sorores, mente deiectam meal Versate primam.

Herc. 116-122

Me vicit? et se vincat et cupiat mori

Ab inferis reversus. hic prosit mihi

Iove esse genitum. stabo et, ut certo exeant

Emissa nervo tela, librabo manu,

120 Regam furentis arma, pugnanti Herculi 
Tandem favebo - scelere perfecto licet

Admittat illas genitor in caelum manus.

hic in V. 117 wird erklärt als ", "herein, in this regard" rather than "at this juncture" " (Fitch) bzw. „hierin” (Billerbeck), was sprachlich genau so unanstößig ist wie die Ellipse des Subjektsakkusativs (Fitch). Indes bleibt der Sinn der Worte hic prosit mihil Iove esse genitum höchst fraglich. Man scheint sie im Lichte des nächsten Satzes so zu deuten, daß es der Juno nützen soll, daß Hercules von Jupiter abstammt, insofern er dann seinen Kindermord gewiß erfolgreich durchführen wird (vgl. die Note des Commelinus: „Iove esse] ut heros fortis sit omniaque sternens obvia, et suos perdat”). Doch hiergegen ergeben sich zwei Bedenken: 1. Kann Juno andeuten, man müsse ein Sohn des höchsten Gottes sein, um mit schweren Waffen hilflose Kinder töten zu können? 2. Wenn schon die Sohnschaft Jupiters Hercules in dieser Hinsicht hilft, so muß ihm gewiß nicht Juno bei seinem Pfeilschuß noch zusätzlich die Hand führen. Die Fortführung spricht also in Wirklichkeit gegen die allgemein akzeptierte Deutung des Commelinus.

Eine der rasenden Juno angemessene Aussage ergibt sich erst, wenn man hic in hunc sc. talem i.e. tam pollutum et tam fractum ändert. „Daß ein solcher (von seiner eigenen Tat so befleckter und so gebrochener) Hercules [vgl. HO 1371 Ta le m subactis Herculem ostende inferis] von Jupiter abstammt, dürfte mir nützen (prosit potentialer Konjunktiv)". Wenn Hercules derart katastrophal ins Elend stürzt, so nützt der Juno sogar die Tatsache, daß er Jupiters Sohn ist, weil er dann der ehebrecherischen Verbindung Jupiters Schande macht. Der zynische Satzanschluß von $h u n c$ prosit mihil Iove esse genitum an die Andeutung von Hercules' Mordtat und seiner anschließenden Verzweiflung (et se vincat et cupiat moril Ab inferis reversus) entspricht exakt V. $121 \mathrm{f}$. scelere perfecto licet/ Admittat illas (sc. tam pollutas) genitor in caelum manus.

Herc. 1179-1182

... in tantis malis

1180 Quid est pudendum? numquid Argivae impotens

Dominator urbis, numquid infestum Lyci

Pereuntis agmen clade nos tanta obruit?

Der vorzeitige Gebrauch des Partizips Präsens, der erforderlich ist, um die Überlieferung zu halten, erscheint möglich, vgl. die Parallelen bei Zwierlein KK $71 \mathrm{f}$. und den Nachtrag LP I 317 (dagegen trifft Billerbecks Parallele Ov. met. 13.580 nicht zu, da Aurora den Tod ihres Sohnes Memnon mitansehen muß, nicht aber seine Leiche vorfindet, wie Billerbeck meint). Auch Fitchs Deutung „agmen Lyci, infestum propter mortem domini" ist letztlich auf eine vorzeitige Verwendung des Partizips angewiesen.

Gegen die Überlieferung spricht indes die Psychologie des aufwachenden Hercules: Dieser hat paradoxerweise zwar seine eigene Mordtat vergessen, befindet sich aber im vollen Bewußtsein all seiner glanzvollen Toten, wie 1169 ff. zeigt, wo er hinter der Ermordung seiner Kinder den vindex irgendeines früheren Feindes sieht. Diesem Hercules, der sich im Moment seiner bevorstehenden Selbsterkenntnis tragischerweise all seiner glanzvollen Taten erinnert (vgl. seinen bekräftigenden Schwur in 1183, 
Per te meorum facinorum laudem precor), traut man nur ungern die komplizierte Überlegung zu, daß trotz seines vollmundigen Ausspruchs tum quisquis comes/ Fuerat tyranni iacuit et poenae comes (896 f.) eben doch ein paar Anhänger des Lycus übrig geblieben seien (so letztlich Zwierlein).

Axelson hatte Vv. 896 f. bereits gegen Withofs Konjektur Lyci/ Iacentis gewandt und vermutete selbst Lyci/ Recentis, wogegen Zwierlein wieder zurecht einwendet, es müsse - trotz 1161 quis Lycus regnum obtinet ? - neben Eurystheus (1179 f.) eher von Lycus selbst als von einem „neuen Lycus” die Rede sein.

Es bleibt der Ausweg, dem gerade aus der Unterwelt zurückgekehrten Hercules (vgl. zu Beginn dieser Rede 1143 ff. Certe redimus ...) den Gedanken zuzuschreiben, Lycus habe mit seiner Schar Entsprechendes vollbracht (bereits in $639 \mathrm{f}$. wurde Lycus in den markigen Worten nuntiet Diti Lycus/ Me iam redisse mit dem Unterweltsgang des Hercules selbst in Verbindung gebracht). Andromache kann in diesem Sinne ihrem toten Gemahl Hector in Hinsicht auf die Erscheinung Achills vorhalten (Tro. 805 f.) lentus et segnis iaces?/ Redit Achilles. Dementsprechend kann man hier annehmen, daß Hercules eine Rückkehr des Lycus mit seinem Gefolge aus der Unterwelt für möglich hält, und schreiben numquid infestum Lyci/ Redeuntis agmen clade nos tanta obruit?. Dann ist Pereuntis einfach Influenzfehler aus dem darunterstehenden Per te (1183). Letztlich denselben Gedanken erstrebte wohl Avantius mit seinem wenig prägnanten Vorschlag Lycil Parentis (= apparentis).

Herc. 1194-1198

Unde hic cruor? quid illa puerili madens

1195 Harundo leto? tincta Lernaea nece:

Iam tela video nostra. non quaero manum:

Quis potuit arcum flectere aut quae dextera

Sinuare nervom vix recedentem mihi?

Einige Herausgeber verbinden das Partizip tincta mit dem vorausgehenden Harundo, andere (im Anschluß an Bothe, vgl. jetzt Billerbeck z.St.) dagegen mit dem folgenden tela, wieder andere nehmen tincta Lernaea nece sc. harundo als eigenen Satz, wobei dann wieder umstritten ist, ob die Ellipse von est zu akzeptieren ist (Zwierlein KK 72) oder ob man mit Leo Lernaea est (lernea A : lernae E) zu schreiben hat (Fitch 2004a: 30 f.).

Fitch im Kommentar z.St. insistiert, daß tincta Lernaea nece "the crucial new discovery" sei und nicht als ",an afterthought or fact of minor importance" hinterherklappen dürfe. Allerdings berfremdet es auch, wenn Hercules nach der oben wiedergegebenen Interpunktion, sich zunächst über den vom Kinderblut getränkten Pfeil wundert (quid illa puerili madens/ Harundo leto sc. vult, wie man wohl supplieren müßte anders interpungiert Withof quid? als eigene Frage) und dann im nächsten Atemzug plötzlich die neue Erkenntnis gewinnt, daß sich auch Lernaeisches Blut daran befindet, aufgrund welcher Tatsache er den Pfeil als seinen eigenen identifizieren kann.

Es wäre vielmehr wünschenswert, daß die verschiedenen Blutfärbungen des Pfeils (wie immer auch Hercules sie zu unterscheiden vermag) im gleichen Satz auftauchen und in ein sinnvolles Verhältnis zueinander treten. Zu diesem Zweck wird man madens in ein finites Verb ändern müssen: 


\begin{abstract}
Unde hic cruor? quid illa puerili madet
1195 Harundo leto tincta Lernaea nece?

Iam tela video nostra: non quaero manum.

„Warum ist jener (berühmte) von Lernaeischem Blut getränkte Pfeil jetzt vom Kinderblute feucht? Es ist nunmehr die eigene Waffe, die ich sehe: So brauche ich nach der tötenden Hand nicht mehr zu fragen".
\end{abstract}

Mit der Junktur illa (,jene berühmte”) .../ Harundo ... tincta Lernaea nece reflektiert Hercules zugleich auf seine Heldentaten (die ja im Mittelpunkt des Bewußtseins des aufwachenden Hercules stehen), mit dem Verbalausdruck puerili madet/ ... leto dagegen auf den befleckenden Kindermord. In der Erkenntnis, daß jener berühmte, vom Lernaeischen Blut getränkte Pfeil zugleich auch vom Kinderblut befleckt ist, realisiert er auf eine geradezu symbolische Weise die Identität des Handelnden in beiden Fällen und damit seine Schuld. Mit dem Besitzer der Waffen ist ja zugleich auch der Täter klar. In Vers 1196 ist also Iam tela video nostra nur als logische Protasis zu non quaero manum zu deuten.

Herc. 1229-1236

... huc arcum date,

1230 Date huc sagittas, stipitem huc vastum date.

Tibi tela frangam nostra, tibi nostros, puer,

Rumpemus arcus; at tuis stipes gravis

Ardebit umbris; ipsa Lernaeis frequens

Pharetra telis in tuos ibit rogos:

1235 Dent arma poenas. vos quoque infaustas meis

Cremabo telis, o novercales manus.

Fitch im Kommentar z.St. stellt richtig heraus, daß man die Junktur meis/ ... telis in Ermangelung eines cum nicht als soziativen Ablativ deuten kann; er präferiert eine Auffassung als Dativ: "the hands brought ill-fortune upon the weapons". Aber in dieser Quasi-Grabrede sollte es um das Unglück der Kinder und nicht um das der ihren Manen gespendeten Waffen gehen.

Billerbeck dagegen nimmt meis/ ... telis als einen von infaustas abhängigen instrumentalen Ablativ. Daß die Hände des Hercules ihr Verderben durch die Waffen ausübten, ist nicht zu bestreiten, aber man versteht nicht, warum man diesen selbstverständlichen Umstand hervorheben muß, wenn es darum geht, auch die schuldigen Hände zusammen mit den „schuldigen” Waffen als Totenopfer zu verbrennen.

Unter den konjekturalen Ansätzen (wenig empfehlenswert Withofs dreifache Änderung infectas notis/ ... sceleris und genauso wenig die Versuche, aus telis neben Cremabo ein ablativisches Synonym für „Feuer” zu gewinnen: taedis Baden, flammis Giardina) ist derjenige am ehesten ernstzunehmen, der sich um die Herstellung eines auf die Kinder gehenden Bezugsdativs zu infaustas bemüht: infaustas meis/ Cremabo teneris versuchte Gronovius, infaustas meis/ Cremabo caris Watt. Aber damit, daß die Hände des Hercules für seine Kinder infaustae, also „unglückverheißend” waren, würde entschieden zu wenig gesagt; dies gilt selbst dann noch, wenn man mit Heinsius zusätzlich infaustas in infestas ändert. Die Hände des Hercules waren für seine Kinder 
schlicht todbringend, nicht nur "feindlich" oder "unglückverheißend". Will man an infaustas festhalten, so scheint man auch solche Versuche, aus meis/ ... telis einen persönlichen Bezugsdativ zu gewinnen, aufgeben zu müssen.

Erstrebenswert erschiene dagegen eine nähere Bestimmung des Verhältnisses der Hände des Hercules zu seinen Waffen. Um meis/ ... telis als soziativen Ausdruck verstehen zu können, müßte man für Cremabo ein Verb des „Mitverbrennens” oder „Hinzufügens" herstellen (man könnte etwa an ein - freilich überlieferungsfernes und in den Tragödien Senecas nicht belegtes - Superaddo denken). Noch besser erschiene freilich eine steigernde Nuance: Die Hände des Hercules sind in noch höherem Maße unheilbringend als seine Waffen. Dann wird man einfach meis am Ende von V. 1235 in magis ändern und telis als komparativen Ablativ deuten. Ähnliche Komparativumschreibungen mit magis am Versende auch in Tro. $886 \mathrm{f}$. Hic forsitan te casus excelso magis/ Solio reponet und Oed. $83 \mathrm{f}$. quoque sit dubius magis/ Status. Dann leitet der komparativische Ausdruck infaustas magis/ ... telis folgerichtig zur rhetorischen Schlußpointe novercales hin.

Herc. 1336-1341

Quoniamque semper sceleris alieni arbiter

Amas nocentes, gratiam meritis refer

Vicemque nostris: redde me infernis, precor,

Umbris reductum, meque subiectum tuis

1340 Restitue vinclis: ille me abscondet locus,

Sed et ille novit ...

Die Kommentatoren suchen das überlieferte Restitue (kaum geschützt durch das syntaktisch anders gestaltete Komplementärmotiv in Phaed. $1218 \mathrm{f}$. ereptos mihi/ Restitue manes) gegenüber Destitue (Axelson), Substitue oder Constitue (Bentley) zu verteidigen (Compesce noch überlieferungsferner Giardina), indem sie Parallelen für gehäufte reKomposita zitieren und für restituere die Bedeutung „den leergewordenen Platz wieder ausfüllen" (Billerbeck) wahrscheinlich machen. Sprachlich ist diese Möglichkeit nicht zu bestreiten, aber das Wechselverhältnis (vicem) zum einstmaligen „Freundschaftsdienst" des Hercules für Theseus wird mit einer anderen Textgestaltung prägnanter: Hercules befreite Theseus aus seinen Fesseln und führte ihn zurück in die Oberwelt, dafür soll ihn Theseus als Gegenleistung seine Stelle in der Unterwelt einnehmen lassen und eben nicht zurückführen, sondern dort zurücklassen. Dieser Aspekt ist für Hercules, der der Welt entkommen will, von zentraler Bedeutung, vgl. $1225 \mathrm{f}$. Tartari ad finem ultimum/ Mansurus ibo. Demnach wird man nicht das Praefix, sondern den Verbalstamm von Restitue verdächtigen und Relinque erwägen, vgl. den Wunsch des Tantalus in Thy. $72 \mathrm{f}$. alveo medius tuo,/ Phlegethon, relinquar igneo cinctus freto. Daß die Wortfolge Relinque vinclis nicht als kakophon gelten müßte, zeigt Sil. Pun. 11.438 Vincere linquentes. 
Stat avidus irae victor et lentum Ilium

Metitur oculis ac decem tandem ferus

Ignoscit annis; horret afflictam quoque,

25 Victamque quamvis videat, haut credit sibi

Potuisse vinci. spolia populator rapit

Dardania; praedam mille non capiunt rates.

Axelsons Konjektur nondum für tandem (23) erscheint sehr empfehlenswert in Anbetracht der Tatsache, daß das ganze Stück mit seinen thematischen Schwerpunkten (Tötung des Astyanax und der Polyxena) die Tatsache zum Gegenstand hat, daß die Griechen Troja auch nach seiner Zerstörung eben nicht verzeihen. Wenn tandem richtig wäre, verstünde man übrigens im unmittelbaren Kontext nicht, warum Troja nach seiner Brandschatzung noch geplündert wird $(18,26)$.

Zwierlein KK 77 versteht horret afflictam quoque (24) in dem Sinne "Agamemnon empfindet Schaudern vor der Größe Trojas ... selbst jetzt noch, als es darniederliegt”. Diese Deutung wird wohl wiederlegt durch die Worte des Odysseus zu Andromache (529 ff.):

Sollicita Danaos pacis incertae fides

530 Semper tenebit, semper a tergo timor

Respicere coget arma nec poni sinet,

Dum Phrygibus animos natus eversis dabit,

Andromacha, vester. augur haec Calchas canit;

Et, si taceret augur haec Calchas, tamen

535 Dicebat Hector, cuius et stirpem horreo.

Die Analogie der konzessiven Ausdrücke cuius et stirpem horreo (535) und horret afflictam quoque (24) legt nahe, daß sich auch horret afflictam quoque auf die Furcht vor den immer noch bedrohlichen Überbleibseln Trojas bezieht.

Bestätigt wird decem nondum ferus/ Ignoscit annis auch durch die späteren Worte des Odysseus (547 ff.):

Veniam dabis, quod bella post hiemes decem

Totidemque messes iam senex miles timet

Aliasque clades rursus ac numquam bene

550 Troiam iacentem. magna res Danaos movet,

Futurus Hector ...

Diese Stelle stünde in eklatantem Missverhältnis zu nicht negiertem ignoscit in V. 24. Daß Hecuba demgegenüber ein in realitätsferner Weise günstigeres Bild von den griechischen Siegern zeichnen sollte, erscheint sehr unwahrscheinlich.

Unter diesen Voraussetzungen wird aber auch die von Zwierlein und Keulen akzeptierte Deutung Kingerys von avidus irae in V. 22 fragwürdig („greedy of (the gratification of) his wrath"). Diese abstrakte Deutung von avidus muß schon in derart kurzem Abstand nach der wesentlich konkreter verständlichen Junktur avidas ... victoris manus (V. 18) befremdlich erscheinen. Insofern in A ira überliefert ist, liegt es nahe, in irae (E) eine nachträgliche Assimilation an avidus zu sehen und für Stat avidus ira 
victor (Stat tumidus ira victor coni. Giardina) ein zu dem folgenden nondum .../ Ignoscit passendes moralisierendes Paradox herzustellen:

Stat victus ira victor et lentum Ilium

Metitur oculis ac decem nondum ferus

Ignoscit annis; horret afflictam quoque.

Vgl. 586 Et quidquid audet victor iratus tumens. Der Feldherr Agamemnon selbst gesteht, daß er bei der Einnahme Trojas den über die bloße Einnahme der Stadt hinausgehenden Zorn seiner Truppen nicht beherrschen konnte (277 ff. affligi Phrygas/ Vincique volui: ruere et aequari solo/ Utinam arcuissem; sed regi frenis nequit/ Et ir a et ardens ensis et victorial Commissa nocti). Zur metaphorisch-paradoxen Verwendung von victus in bezug auf die Griechen vgl. Ag. 183 Sine hoste victus marcet ac Veneri vacat.

Tro. 51-56

Placare quem non potuit a caede effera

Mortalis aevi cardinem extremum premens

Superique testes sceleris et quoddam sacrum

Regni iacentis? ille tot regum parens

55 Caret sepulcro Priamus et flamma indiget

Ardente Troia ...

Zwierlein KK 79 akzeptiert das quoddam der Hauptüberlieferung trotz Axelsons Hinweis, daß in Anbetracht von Sen. epist. 55.4 quiddam sacrum wahrscheinlicher wäre (Fitch 2004a: 35 betont jetzt den substantivischen Charakter von sacrum). Zuvor hatte Zwierlein (vgl. LP I 149 f.) im Anschluß an Carlsson die in jüngeren Handschriften überlieferte Variante quondam gebilligt (so jetzt auch Keulen im Anschluß an Fantham und Carlsson) und durch Verg. Aen. $2.556 \mathrm{f}$. gestützt (tot quond a m populis terrisque superbum/ Regnatorem Asiae). Gegen die frühere Auffassung wird im KK geltend gemacht, daß sich quondam nur auf eine "fernere Vergangenheit" beziehen könne, "der Sturz Trojas aber wird eben erst vollzogen”: „Gemeint ist das eine Art heiligen Schauers Erregende des gefallenen Königtums = der gewissermaßen heilige Schauer, den man beim Anblick gefallenen Königtums zu empfinden pflegt".

Indes erscheint bei beiden Lesarten fraglich, inwiefern der Respekt vor der Größe daniederliegenden Königtums Pyrrhus in der letzten Nacht Trojas (als das bislang zähen Widerstand leistende Troja gerade erst eingenommen wurde) Pyrrhus von der Ermordung des zu diesem Zeitpunkt noch amtierenden Königs Priamus (vgl. 162 bello moriens sc. Priamus) hätte abhalten sollen. Wenn man die Ausdrucksweise Senecas im Sinne Zwierleins versteht, müßte man annehmen, daß Troja zum Zeitpunkt der Ermordung des Priamus längst eingenommen war; dies war aber zumindest gemäß dem zweiten Aeneis-Buch nicht der Fall (trotz Hecubas subjektiv differenzierender Formulierung Troia iam vetus est malum in V. 43), sondern die Ermordung des Priamus ereignet sich im Zuge der Wirren des nächtlichen Kampfes in der Stadt. Insofern kann der Respekt vor der einstigen Größe einer Königsherrschaft kaum als Faktor genannt werden, der Pyrrhus von seiner Tat hätte abhalten sollen. 
Viel plausibler ist es, die Worte in der Textgestalt quondam sacrum/ Regni iacentis auf den einstigen Großmut Achills bei der Auslösung von Hectors Leiche (im Gegensatz zur unerbittlichen Grausamkeit des Pyrrhus) zu beziehen, welchen Priamus selbst in Verg. Aen. 2.540-543 dem Pyrrhus vergeblich vorhält:

At non ille, satum quo te mentiris, Achilles

Talis in hoste fuit Priamo; sed iura fidemque

Supplicis erubuit corpusque exsangue sepulcro

Reddidit Hectoreum meque in mea regna remisit

(vgl. auch 312 f. Saevo peremptus ense quod Priamus iacet,/ Supplex paternus). Demnach bedeuten die Worte "der einstmals [sc. noch von Achill geachtete] heilige Status einer am Boden liegenden Königwürde” (regnum nicht etwa „Königreich”, sondern „Königswürde", vgl. die auf Achills Großmut gemünzten Worte des Pyrrhus in 327 Est regis alti spiritum regi dare): Der greise König hatte sich ja vor Achill buchstäblich zu Boden geworfen (zur Motivik vgl. Phaed. 666 f. en supplex iacet/ Adlapsa genibus regiae proles domus). In der Fortführung mit den Worten ille tot regum parens/ Caret sepulcro Priamus ist dann wahrscheinlich impliziert, daß derjenige, der für seinen Sohn Hektor noch eine Bestattung ermöglichte, selbst kein Grab mehr erlangte.

Tro. 59-62

60

Hic Hectoris coniugia despondet sibi,

Hic optat Heleni coniugem, hic Antenoris;

Nec dest tuos, Cassandra, qui thalamos petat.

Mea sors timetur, sola sum Danais metus.

Als Antithese zu den übrigen trojanischen Sklavinnen ist die Junktur Mea sors ... sola gefordert, und die Worte sum Danais metus ergeben im Munde der Greisin Hecuba ein glänzendes Paradoxon. Dementsprechend ist die Interpunktion zu ändern.

Tro. 178-181

Tum scissa vallis aperit immensos specus

Et hiatus Erebi pervium ad superos iter

180 Tellure fracta praebet ac tumulum levat.

Emicuit ingens umbra Thessalici ducis/ ...

Nach wie vor (trotz Keulen ad loc.) gilt die bei Zwierlein KK 83 im Anschluß an Axelson gestellte Diagnose, daß der Spalt den Grabhügel nicht erheben kann. Zwierlein erwägt als konjekturale Lösung die Herstellung von tumulo levis in V. 180 (dann der Satzschluß am Versende zu tilgen), wobei levis auf die topische Leichtfüßigkeit Achills zu beziehen sei, „, das Wort darf nicht auf die Körperlosigkeit der Unterweltsschatten bezogen werden ...; dies würde sich nicht mit ingens umbra vertragen: Achill scheint hier in bedrohlicher Größe".

Wenn demnach der Totenschatten Achills als "gewaltig" geschildert wird, so liegt es nahe, diese Vorstellung auch zur Deutung bzw. Emendation von tumulum levat (tumulum secat sc. hiatus versucht zuletzt Giardina) nutzbar zu machen und levare nicht in dem Sinne „emporheben”, sondern als „erleichtern” zu deuten (dies erwägt 
Fitch 2004a: 38: „The phrase tumulum levat means that the weight of the gravemound is eased momentarily, allowing the emergence of Achilles' shade", der allerdings danach wieder zur Deutung "emporheben” zurückkehrt: "that process ... heaves up the gravemound"). Wenn der Totenschatten Achills (entgegen dem Topos der Körperlosigkeit der Schatten) "gewaltig” ist, so wird er durch seinen Austritt sein Grab zeitweise "erleichtern”, womit zugleich der Topos der schwer auf einem Toten lastenden Erde (vgl. Fitch 1.c.) umgekehrt wird: Hier lastet nicht die Erde auf dem Leichnam, sondern der gewaltige Tote lastet beschwerend auf seinem Grab (ingens vom Gewicht: ThLL VII 1, 1537, 56-65) und erleichtert dieses durch seinen zeitweiligen Austritt. Die ganze Schilderung ist abgestellt auf den Aspekt der Gewaltigkeit selbst des toten Achill (motivisch ähnlich ist Oct. 522 non leves umbras tegit sc. Pompei et Antonii Aegyptus, wenn hier tatsächlich eine Negation herzustellen ist für das überlieferte nunc [non M. Müller, nec Zwierlein]). Man hat mit Zwierlein den Satzschluß nach 180 zu tilgen und zu lesen:

Tum scissa vallis aperit immensos specus

Et hiatus Erebi pervium ad superos iter

180 Tellure fracta praebet ac tumulum levans

Emicuit ingens umbra Thessalici ducis/ ...

levare in dem Sinne „einen Ort verlassend erleichtern” auch in Herc. $1051 \mathrm{f}$. ut somno gravis/ Vis victa morbi pectus oppressum levet. Zur Motivik ist Stat. Theb. $5.430 \mathrm{zu}$ vergleichen, wo anläßlich eines Besuchs der Götter auf der Erde Atlas erleichtert aufatmet (paulum respirat caelifer Atlas).

Tro. 301-305

O tumide, rerum dum secundarum status

Extollit animos, timide, cum increpuit metus,

Regum tyranne! iamne flammatum geris

Amore subito pectus ac veneris novae

305

<.....................................>

Solusne totiens spolia de nobis feres?

Zwierlein KK 91 wendet sich zurecht gegen alle Versuche, V. 303 in seiner überlieferten Form zu konstruieren (Fitch 2004a: 43 schreibt jetzt mit Bentley am Anfang von V.304 Amoris aestu und akzeptiert die pleonastische Junktur Amoris ... ac veneris novae; einen fragwürdigen Pleonasmus produziert auch Bothes Versuch flammatum ... Amore subito pectus ac veneres novas). Als Alternative zu der von Gronovius nach V. 303 angesetzten Lücke nach V. 303 wäre vielleicht eine Abänderung von $a c$ in en zu erwägen: en begegnet häufig in dieser metrischen Stellung bei Seneca, in höhnischer Frage auch in Phaed. 684 dignus en stupris ego?. Die pleonastische Fügung Amore subito ... veneris novae („,plötzliche Lust auf ein neues Liebesverhältnis bzw. auf eine neue Geliebte", vgl. Ag. 188 f. nunc novum vulnus gerens/ Amore Phrygiae vatis incensus furit) läßt sich rechtfertigen durch Ov. met. 14.634 Hic amor, hoc studium; Veneris quoque nulla cupido est.

In V. 305 wird Solus(ne) im Sinne der geläufigen Verstärkung von totiens durch unus erklärt. Logisch angemessener erschiene indes, insofern Pyrrhus sagen will, daß 
sich Agamemnon seine erotischen Objekte immer auf Kosten nur seiner Familie holt, also Solisne ... de nobis. Dann erhielten die beiden anaphorisch mit -ne eingeleiteten Fragen einen engen logischen Zusammenhalt: „Schon wieder plötzliche Lust auf ein neues Liebesabenteuer? Und immer nur wir Deine Opfer?". Zu dieser Satzfolge vgl. Phaed. 684-686

... dignus en stupris ego?

685 Scelerique (num Scelerine ?) tanto visus ego solus tibi

Materia facilis? ...

Tro. $365-370$

... non tamen nostras tenet

Haec una puppes causa: nobilior tuo,

Polyxene, cruore debetur cruor.

Quem fata quaerunt, turre de summa cadat

Priami nepos Hectoreus et letum oppetat.

370 Tum mille velis impleat classis freta.

Der Übergang von Polyxena zu Astyanax wird erst dann verständlich, wenn man den Relativsatz Quem fata (sc. non Achilles) quaerunt an cruor anschließt und nach quaerunt einen Doppelpunkt setzt.

Tro. $412-415$

... Ilium vobis modo,

Mihi cecidit olim, cum ferus curru incito

Mea membra raperet et gravi gemeret sono

415 Peliacus axis pondere Hectoreo tremens.

Die Frage, ob sich ferus als substantiviertes Adjektiv auf den nicht genannten Achill oder auf den im übernächsten Vers erwähnten Wagen des Peliden bezieht, kann man sehr kontrovers diskutieren (vgl. Keulen z.St.). Dieses kleine formale Defizit (vgl. auch die unschöne Doppelung curru - axis) weist bereits auf einen schwereren inhaltlichen Anstoß: In einem Zusammenhang, wo Andromache die Schleifung von Hektors Leichnam als den eigentlichen Untergang Trojas bezeichnet, ist die andersartige poetische Figur, den Körper des Geliebten als „die eigenen Glieder” zu bezeichnen (von Keulen belegt durch Ov. met. $11.700 \mathrm{f}$. und 13.495), schlechterdings unpassend (trotz der forcierten Korrespondenz Mihi .../ Mea): In diesem Zusammenhang vertritt Hektors Leiche eben symbolisch die ganze Stadt Troja und nicht nur Andromaches Glieder. Das schwere Geräusch des geschleiften Leichnams (gravi gemeret sono) vertritt der Andromache den Lärm der stürzenden Stadt (Ilium .../ Mihi cecidit olim, motivisch wohl eine Umkehrung von Ov. epist. 1.51 Diruta sunt aliis, uni mihi Pergama restant), was durch die dazwischentretende pathetische poetische Figur „meine eigenen Glieder wurden geschleift" völlig verunklart wird. Man wird die Worte ferus curru incito/ Mea membra raperet et als Binneninterpolation ausscheiden müssen. 
Tro. $757-759$

Virtus Ulixis Danaidis nota est satis

Nimisque Phrygibus. non vacat vanis diem

Conterere verbis: ancoras classis legit.

In Anbetracht der Tatsache, daß die Tötung des Astyanax nach der Calchas-Prophezeiung eine Voraussetzung für den Aufbruch der Griechen aus Troja ist (vgl. im Munde des Odysseus auch $552 \mathrm{f}$. Haec una naves causa deductas tenet, / Hic classis haeret und 813 Abripite propere classis Argolicae moram), kann der Aufbruch hier noch nicht im Indikativ als ein zeitlich urgierendes (ohnehin bevorstehendes) Factum erwähnt werden wie im Schlußvers des Stückes (1179 Iam vela puppis laxat et classis movet). Der anonyme Rezensent von SHT hält die Äußerung des Odysseus für „a specious reason to break off the interchange". Insofern E das Futurum leget hat, läge die Herstellung von legat nicht fern, vgl. den Schlußvers der Calchas-Prophezeiung (370 Tum mille velis impleat classis freta).

Tro. 799-806

800 Lacerosque crines excipe et plenus mei Occurre patri; pauca maternae tamen Perfer querelae verba: „si manes habent Curas priores nec perit flammis amor, Servire Graio pateris Andromachen viro,

805 Crudelis Hector? lentus et segnis iaces? Redit Achilles." ...

Der topische Kondizionalsatz si manes habent/ Curas priores nec perit flammis amor bildet logisch die Voraussetzung dafür, daß die Mitteilung einer solchen querela an Hector überhaupt sinnvoll bzw. möglich ist. Insofern gehört er zum Imperativ pauca maternae tamen/ Perfer querelae verba und sollte nicht als ein Teil der oratio recta die pauca ... / ... querelae verba erweitern, zumal die vorwurfsvolle Frage Servire ... pateris ...? durch eine solche Protasis nur geschwächt wird.

Zum Topos verweist der anonyme Rezensent der SHT auf Bonds Kommentar zu Eur. Her. 490-496; dort geht der Bedingungssatz (490 f.), genau wie hier, der dem Toten übermittelten Oratio recta (492 ff.) voraus.

Tro. 917-924

$$
\text { ... causa bellorum fui }
$$

Tantaeque Teucris cladis? hoc verum puta,

Spartana puppis vestra si secuit freta;

920 Sin rapta Phrygiis praeda remigibus fui

Deditque donum iudici victrix dea, Ignosce †Paridi: iudicem iratum mea

Habitura causa est: ista Menelaum manent

Arbitria ... 
Zwierlein KK 104-106 erweist, daß Ignosce Paridi in V. 922 nicht zu halten ist und daß die Antithese nicht zwischen zwei angeklagten Personen, sondern zwischen Ignosce und iudicem iratum (was sich beides auf Helena beziehen muß) besteht; als mögliche Verbesserungen werden raptae (Schrader) und praedae (Leo) erwogen (zwei Begriffe, die jedoch schon in V. 920 in bezug auf Helena angewandt wurden), ferner captae als Zwierleins eigene Modifikation zu Schraders Versuch (trepidae von Giardina empfiehlt sich kaum).

Keulen ad loc. verteidigt wieder die Überlieferung im Sinne einer Antithese zwischen zwei angeklagten Personen und kritisiert an der konjekturalen Textfassung mit raptae oder praedae die Härte des Übergangs: „Both praedae and raptae would involve an akward transition: „forgive me - I shall have an enraged judge" ". Ähnlich jetzt auch Fitch 2004a: 54 n. 27 (der wie Keulen Ignosce Paridi zu verteidigen versucht): „The relationship might be: „You at least could forgive me, though my next judge will be more hostile," but this would require either tu quidem or a comparative adjective".

Insofern es nach dem ganzen Zusammenhang klar ist, daß sich Ignosce auf Helena bezieht, benötigt man eigentlich keinen Dativ. Stattdessen wird man ein Prädikativum zu Ignosce suchen, so daß sich - gemäß Fitchs oben zitierter Forderung - eine vollkommene Antithese zu iudicem iratum ergibt (Ignosce entspricht iudicem, das zu suchende Prädikativum iratum). Ich erwäge Ignosce facilis: iudicem iratum meal Habitura causa est. Zur Antithese vgl. [Quint.] decl. min. 291.1 ingressurus actionem interrogo qualem patrem velis: gravem et severum an facilem et ignoscentem. Helena fordert Andromache, die sie noch in V. 906 als iudex infestus ansah, in etwas wirklichkeitsfremder Weise auf, ihr mit freundlicher Geneigtheit zu verzeihen, da sie ja einen zornigen Richter später in dem von ihr betrogenen Menelaus haben wird. Einen ähnlich wirklichkeitsfremden Wunsch äußert die Amme in einem Gebet an Hecate in Phaed. 414: Det facilis aures (Hippolytus soll das Anliegen der Phaedra mit freundlicher Geneigtheit anhören). Vgl. auch Herc. 360 f. (Lycus zu Megara: facilis meal Parumper aure verba patienti excipe).

Tro. 981-998

Quis tam impotens ac durus et iniquae ferus

Sortitor urnae regibus reges dedit?

Quis tam sinister dividit captas deus?

Quis arbiter crudelis et miseris gravis

985 Eligere dominos nescit et saeva manu

Dat iniqua miseris fata? quis matrem Hectoris

Armis Achillis miscet? ad Ulixem vocor:

Nunc victa, nunc captiva, nunc cunctis mihi

Obsessa videor cladibus: domini pudet,

990 Non servitutis. [Hectoris spolium feret

Qui tulit Achillis?] sterilis et saevis fretis

Inclusa tellus non capit tumulos meos.

Duc, duc, Ulixe, nil moror, dominum sequor;

Me mea sequentur fata (non pelago quies

995 Tranquilla veniet, saeviet ventis mare) 
Et bella et ignes et mea et Priami mala.

Dumque ista veniant, interim hoc poenae loco est:

Sortem occupavi, praemium eripui tibi.

Über die von Zwierlein aufgenommene Tilgung Leos der Verse 990 a/ 991 b hinaus scheint man auch noch mit Peiper die Worte saeva manu/ Dat iniqua miseris fata? quis in 985 f. beseitigen zu müssen (Zwierlein KK 107 setzt die ungewöhnliche Form dieser Binneninterpolation dagegen). Denn an Quis tam impotens ac durus et iniquae ferus/ Sortitor urnae, Quis tam sinister ... deus und Quis arbiter crudelis et miseris gravis fügt sich schon formal ein nacktes quis unbefriedigend; außerdem wird in den ersten drei Gliedern jeweils ein "technisches" Versagen bei der Zulosung beklagt (regibus reges dedit, dividit captas und Eligere dominos nescit, was durch matrem Hectoris/ Armis Achillis miscet ausgeführt wird), während saeva manu/ Dat iniqua miseris fata kein solches technisches Versagen ausdrückt, sondern nur allgemein die Mißlichkeit für die unglücklichen Betroffenen beschreibt, und dies mit einer unerträglichen Wiederholung von miseris aus V. 984.

Aber auch damit scheint die Reaktion der Hecuba auf ihre Zulosung noch nicht ihre ursprüngliche Form zurückerlangt zu haben. Denn die Klage über den zugelosten Herrn Odysseus (989 f. domini pudet,/ Non servitutis) wird erst in V. 993 wiederaufgegriffen durch das nachdem vorher Gesagten paradox anmutende dominum sequor. Diese Paradoxie (Hecuba bezeichnet zunächst ihren Herrn Odysseus als unerträglich, bekennt sich dann aber paradoxerweise doch zu ihm, was dann durch die Erwartung, ihn durch ihr eigenen Unglück mitzuvernichten, erklärt wird) dürfte von Seneca wesentlich schärfer fokussiert worden sein, als es in der uns vorliegenden interpolierten Fassung der Fall ist.

Der Gedanke, daß das karge Ithaka Hecubas Grab nicht zu fassen vermag (991 f.), schiebt sich in m.E. unerträglicher Weise zwischen die komplementären Versschlüsse domini pudet (989) und dominum sequor (993). Ein Anfangsverdacht gegen das Dazwischenstehende ist schon durch die Tatsache, daß Leo 990 a/ 991 b schlüssig als Wiederaufnahme des Themas aus 986 f. erwiesen hat (vgl. Zwierlein KK 107 f.). Es erscheint aber auch abwegig, daß eine Hecabe, der das Los das Scheusal Odysseus als Herrn zuweist, ihre Reflexionen über diesen Herrn unterbricht durch eine Überlegung über die geographische Unzulänglichkeit ihres künftigen neuen Wohnorts (anders steht es mit der Reflexion der Iole über Trachis als künftigen Wohnort in HO 133 ff., wo die ganze Partie nicht von vorneherein durch den Gedanken an einen widerwärtigen Herrn bestimmt ist). Besonders abwegig erscheint aber, daß Hecuba, nachdem sie betont hat, sich nicht der Tatsache ihres Sklavenstatus, sondern nur der Identität ihres Herrn zu schämen, im nächsten Atemzug auf die unerträglichen geographischen Verhältnisse der Insel zu sprechen kommt.

Diese Reflexion ist auch für sich gesehen gedanklich höchst unbefriedigend: non capit (992) impliziert zwingend, daß Ithaka zu klein ist für Hecubas Grab. Sollte eine Frau in der Lage Hecubas tatsächlich eine weitläufige Grabanlage erwarten und unter diesem Gesichtspunkt Ithaka ablehnen?

Man könnte allenfalls hinter dem Plural tumulos meos mehr als nur das persönliche Grab Hecubas verstehen („Hecubas Gräber” gewissermaßen als Metonymie für das sich in ihren gestorbenen Angehörigen manifestierende Unglück). Doch inwiefern könnte dann gesagt werden, daß Ithaka für all diese Gräber zu klein sei? An eine 
tatsächliche Überführung der Asche ihrer Angehörigen konnte Hecuba ja kaum denken. Im metaphorischen Sinne aber („,die Insel ist zu eng für die ganze Fülle meines Unglücks") wirkt der Gedanke ziemlich frostig und bringt die Verzweiflung Hecubas in der aktuellen Situation der Zulosung kaum passend zum Ausdruck.

Schließlich ergeben sich in Vv. 993 f. nach der Überlieferung auch formale Schwierigkeiten. Wenn Hecuba tatsächlich Odysseus apostrophiert mit Duc, duc, Ulixe, so müßte man anstatt dominum sequor strenggenommen auch te, domine, sequor erwarten. Axelson wollte die Apostrophe sogar noch in den folgenden Vers weiterführen, indem er Te mea sequentur fata erwog. In Wirklichkeit dürfte die nicht fortgeführte Apostrophe ausschließlich auf das Konto eines Interpolators gehen. Als ursprünglich senecanische Fassung vermute ich:

Quis tam impotens ac durus et iniquae ferus
Sortitor urnae regibus reges dedit?
Quis tam sinister dividit captas deus?
Quis arbiter crudelis et miseris gravis
985 a/986 b
Eligere dominos nescit et matrem Hectoris
Armis Achillis miscet? ad Ulixem vocor:
Nunc victa, nunc captiva, nunc cunctis mihi
Obsessa videor cladibus: domini pudet,
990 a/ 993 b Non servitutis - nil moror dominum, sequor:
Me mea sequentur fata (non pelago quies
995 Tranquilla veniet, saeviet ventis mare)
Et bella et ignes et mea et Priami mala.
Dumque ista veniant, interim hoc poenae loco est:
Sortem occupavi, praemium eripui tibi.

Mit nil moror dominum (vgl. Oed. 926 quid poenas moror) wird in überraschender und paradoxer Weise domini pudet umgekehrt. Die Erklärung für diese Meinungsänderung erfolgt, indem Hecuba an sequor die Anküdigung anfügt, ihr eigenes "Gefolge" (in Gestalt ihres ganzen Unglücks) mitzunehmen (Me mea sequentur fata "Mir wird mein eigenes spezielles Gefolge folgen”; zur Motivik vgl. Oed. 652 f. Letum Luesque, Mors Labor Tabes Dolor,/ Comitatus illo dignus, excedent simul; 1057-1060 Mortifera mecum vitia terrarum extraho:/ Violenta Fata et horridus Morbi tremor,/ Maciesque et atra Pestis et rabidus Dolor, / Mecum ite, mecum. ducibus his uti libet).

Der Interpolator der Verse 990 b-993 a hat 1. eine Dublette zu 986 f. geliefert, 2. einen in den Gesamttenor der Rede nicht passenden Rekurs auf Odysseus' karge Heimatinsel eingeflochten (nach dem Vorbild der Polemik Agamemnons gegen Pyrrhus, 339 f. Hos Scyros animos? ... Inclusa fluctu ...; das Motiv der Enge von Ithaka stammt dagegen aus dem vorigen Chorlied, 856 Neritos parva brevior Zacyntho, dem der Interpolator überhaupt die Inspiration zu einer solchen geographischen Reflexion über Hecubas Zielort entnommen zu haben scheint) und 3. die vermeintliche Junktur dominum sequor durch eine (formal unpassende) Apostrophe Duc, duc, Ulixe präpariert. 
Tro. 1152-1154

Conversa ad ictum stat truci vultu ferox.

Tam fortis animus omnium mentes ferit,

Novumque monstrum est Pyrrhus ad caedem piger.

Die Partie gewinnt stilistisch, wenn man Novumque monstrum noch zu ferit zieht (vgl. Thy. 703 Movere cunctos monstra), est in V. 1154 als falsches Glossem tilgt und stattdessen Doppelpunkt setzt. Für Bentleys Tilgung des ganzen Verses 1153 besteht damit kein Anlaß mehr (vgl. Zwierlein LP I 166).

Phoen. 22-26

\author{
Vel qua alta maria vertice inmenso premit \\ Inoa rupes, qua scelus fugiens novum \\ Novumque faciens mater insiluit freto \\ 25 Mersura natum seque - felices quibus \\ Fortuna melior tam bonas matres dedit.
}

Das am Ende von V. 23 überlieferte suum wird jetzt wieder verteidigt von Fitch (2004a: 65), der es für möglich hält, daß sich Seneca hier gegen Ov. met. 4.512 ff. einer obskuren (und wohl sekundären) Sagenversion anschließt, wonach Inos Sprung ins Meer nicht durch den Kindermord des Athamas, sondern durch die Entdeckung ihrer eigenen Intrige gegen Phrixus veranlaßt wird. Selbst unter dieser Voraussetzung aber wäre die Antithese scelus fugiens suum/ Novumque faciens unpräzise, da ja auch das neue Verbrechen das ihrige ist.

Zwierlein (LP I 390 und 408) und die Kommentatoren Hirschberg und Frank nehmen dagegen an, daß Seneca der ovidischen Version folgt, und schreiben mit Peiper novum für suum.

Die suggestive stilistische Wirkung dieser konjektural gewonnen Wortaufnahme sollte jedoch nicht darüber hinwegtäuschen, daß ein novum am Ende von V. 23 es unmöglich macht, daß unzweifelhafte Novum am Anfang von V. 24 in seinem natürlichen Sinne zu fassen: Diejenige Frau, die vor dem einen Verbrechen flieht, richtet dabei tragischerweise ein neues Verbrechen an. Wenn man dagegen schon am Ende von V. 23 novum liest, kann man man novum scelus nur in dem Sinne ein „neuartiges (ungeheures) Verbrechen" fassen - sicher idiomatisch und gut-senecanisch, aber dem offensichtlichen Ductus der Partie („ein neues Verbrechen statt des durch die Flucht vermiedenen") entgegenlaufend.

Auch die übrigen Konjekturen stellen sämtlich attributive Erweiterungen zu scelus her, entweder einen Genitiv (viri Gronovius, sui Baden) oder ein Adjektiv (ferum Bothe, vetus Viansino). Gerade der Vorschlag von Viansino lehrt, daß der Versuch, eine scharfe Antithese zu novum scelus (wenn man diese Wendung wie oben erläutert versteht) zu gewinnen, zum Scheitern verurteilt ist (eher noch als vetus könnte man gemäß $A g$. 149 Piget prioris et novum crimen struis? am Ende von V. 23 ein prius versuchen, aber das Verbrechen des Athamas liegt eben - anders als der Ehebruch Clytemestras - noch nicht länger zurück, sondern gehört der unmittelbaren Gegenwart an; außerdem 
würde eine konzinne Antithese zweier Zeitbegriffe wie vetus - novum oder prius novum über die Tatsache hinwegtäuschen, daß das alte Verbrechen einen anderen Urheber [Athamas] als das neue [Ino selbst] hat).

Man benötigt eben überhaupt kein Attribut zu scelus: Die Tragik der Ino liegt gerade darin, daß sie, indem sie einem Verbrechen (dem drohenden zweiten Kindermord des Athamas) entflieht, ein neues Verbrechen anrichtet; die Antithese besteht nicht zwischen zwei Attributen, sondern zwischen den Partizipien fugiens und faciens und wird nur noch weiter geschärft durch das zu faciens scelus hinzutretende novum (das angerichtete Verbrechen ist eben „neu” gegenüber dem vermiedenen); vergleichbar ist Phoen. 269 Scelerisque pretium maius accepi scelus. Im Sinne dieser Tragik der Ino-Figur wird man den Aspekt des Zusammentreffens forcieren, daß Ino durch denselben Sprung, mit welchem sie dem einem Verbrechen entfloh, zugleich ein neues beging. Ich erwäge eine Abänderung des überlieferten suum in simul.

Phoen. 173-176

Ades atque inertem dexteram introrsus preme

Magisque merge: timida tunc parvo caput

175 Libavit haustu vixque cupientes sequi

Eduxit oculos ...

Besser als durch die nach Hirschberg z.St. exzeptionelle Junktur parvo .../ ... haustu wird der Gedanke zu starker Zurückhaltung zum Ausdruck gebracht durch parco .../ ... haustu (zur Juxtaposition timida ... parco vgl. Ov. ars 1.183 Parcite natales timidi numerare deorum). Die so hergestellte Junktur scheint eine höchst zynische, auf maßvollen Alkoholgenuß gehende Metapher zu implizieren, vgl. Manil. astron. $5.244 \mathrm{f}$. nec parce vina receptal Hauriet; Petr. sat. 130.7 hausi parcius merum. Statius verwendet eine ähnliche, Zurückhaltung ausdrückende Junktur von einem eiligen geschwisterlichen Kuß zwischen Diana und Apoll, Theb. $9.668 \mathrm{f}$. libandaque fratril Parcius ora tulit.

Phoen. 354-362

... non satis est adhuc

355 Civile bellum: frater in fratrem ruat.

Nec hoc sat est: quod debet, ut fiat nefas

De more nostro, quod meos deceat toros:

Date arma matri - nemo me ex his eruat

Silvis: latebo rupis exesae cavo

360 Aut saepe densa corpus abstrusum tegam.

Hinc aucupabor verba rumoris vagi

Et saeva fratrum bella, quod possum, audiam.

Gronovs sicher richtige Herstellung von Date arma matri für in den Haupthandschriften überlieferte Date arma patri scheint nicht auszureichen, um die durch den Zusammenhang geforderte Steigerung des Bruderkampfs zu gewinnen. Gronov selbst dachte an eine Ausrüstung der Mutter mit einem Schwert zum Selbstmord (so auch Hirschberg 
z.St.), Frank deutet dagegen in sprachlich dubioser Weise „inflict violence upon your mother" (Date $=$ inferte?).

Ein wirkliches Pendant zum eigenen Frevel des Oedipus ergibt sich, wie Fantham gesehen hat, erst dann, wenn von einem Inzest mit der Mutter die Rede ist. Diesen Gedanken in die Worte Date arma matri hineinzulesen ist jedoch nicht möglich, da 1. der sexuelle Gebrauch von arma der Tragödie unangemessen ist und 2. sich auch in epigrammatischer Literatur keine Parallele für den geforderten Gebrauch von arma dare nachweisen läßt.

Man wird arma im herkömmlichen Sinne verstehen und Date als Korruptel ansehen - am ehesten als ein falsches Glossem, welches eine Aposiopese erklären sollte. Ich erwäge Post arma matri (sc. coite). Der Versauftakt Post arma wie Tro. 591; ein ähnlich idiomatischer, auf die Verbrechen des thebanischen Hauses bezüglicher Ausdruck begegnet auch in Phoen. 50 timeo post matrem omnia. Die Söhne sollen nach dem frevelhaften Waffengang Inzest üben, wie Ödipus selbst nach der Töung des Vaters seine Mutter schändete (vgl. $267 \mathrm{f}$. in patrios toros/ Tuli paterno sanguine aspersas manus); in dieser Abfolge (erst frevelhafter Waffengebrauch, dann Inzest) liegt die von Oedipus forcierte Entsprechung zwischen seiner eigenen „Biographie” und seinen Söhnen (in Phoen. 109 ff. hat er seinen Söhnen gerade dasjenige Schwert für ihren Frevel überlassen, mit welchem er selbst einst Laius tötete). Mit der hergestellten Aposiopese bricht Oedipus die Ausmalung der letzten Konsequenz seiner Phantasie ab und vermeidet zugleich das verbum obscenum.

Phoen. 434-442

435 Haesere bella, iamque in alternam necem

Illinc et hinc miscere cupientes manus

Librata dextra tela suspensa tenent.

Paci favetur, omnium ferrum latet

Cessatque tectum - vibrat in fratrum manu.

440 Laniata canas mater ostendit comas,

Rogat abnuentis, irrigat fletu genas.

Negare matri, qui diu dubitat, potest.

Der letzte Vers wird allgemein als ein pessimistische Spekulation des Boten aufgefaßt, in der man zu dubitat in Antithese zu Negare ein parere zu ergänzen hat.

Aber die Prognose Negare matri, qui diu dubitat, potest ist sinnlos, wenn die beiden Söhne bereits im vorigen Vers als abnuentes bezeichnet wurden, es sei denn man gibt den Verben negare und abnuere eine verschiedene Bedeutung (der anonyme Rezensent der SHT paraphrasiert: "the brothers are unreceptive but do not give a definitive rebuff"). Man wird den letzten Vers vielmehr als ungläubigen Fragesatz interpungieren, der einen ungläubigen Kommentar zu abnuentes anfügt: „Kann etwa derjenige seiner Mutter den Wunsch noch ausschlagen, der schon lange zögert?". Dann geht dubitat auf das seit V. 434 ausgemalte Innehalten beider Parteien, welches (trotz V. 439) auch die beiden Söhne einschließt. Der Bote redet sich die Sache schön, als ob die Sache mit dem zeitweiligen Innehalten beider Parteien bereits zugunsten der Mutter entschieden sei. 
Phoen. $480-483$

... redde iam capulo manum,

Astringe galeam, laeva se clipeo inserat:

Dum frater exarmatur, armatus mane.

Tu pone ferrum, causa qui ferri es prior.

Zwierlein nimmt in der Oxford-Ausgabe causa qui ferri es prior zusammen. Hirschberg z.St. wendet sich ausdrücklich gegen ein mögliches Komma nach ferri es und die damit verbundene prädikative Beziehung von prior auf Tu pone ferrum; vielmehr drücke „das [neben causa ... ferri] scheinbar abundante prior" aus, „daß auch Polynices am Krieg schuldig ist". Frank z.St. schließt sich dieser Deutung an.

Mit solcher Interpunktion wird indes die Möglichkeit einer logisch schärferen Ausdrucksweise preisgegeben („Du, der Du der Grund des bewaffneten Kampfes bist, lege dementsprechend auch als erster die Waffen nieder"), wie sie durch den Zusammenhang gefordert wird: Denn es steht ja außer Frage, daß sich nach Jokastes Willen beide Söhne entwaffnen sollen, und daß hier nur dem Bedenken des Polynices (478480 a) dadurch entgegengekommen wird, daß sich Eteocles vor ihm als erster entwaffnen soll.

Der anonyme Rezensent der SHT verweist zudem auf die analoge Verbindung von prior mit einem Imperativ in V. 464 iunge complexus prior.

Überdies ist die Sperrung zwischen dem zur Entwaffnung auffordernden Imperativ und dem prädikativ zu diesem gehörigen prior durch einen auf die zweite Person bezüglichen Relativsatz gedeckt durch das vergilische Vorbild dieses pathetischen Bürgerkriegsmotivs (Verg. Aen. 6.832-835, Anchises in der Heldenschau zu Caesar und Pompeius):

Ne, pueri, ne tanta animis adsuescite bella

Neu patriae validas in viscera vertite viris;

Tuque prior, tu parce, genus qui ducis Olympo,

Proice tela manu, sanguis meus!...

Med. 134-136

... funestum impie

135 Quam saepe fudi sanguinem - et nullum scelus

Irata feci: saevit infelix amor.

Zwierlein KK 139 f. wehrt sich gegen Primmers Deutung („Wie oft habe ich schon impie Blut vergossen - und dabei habe ich bis jetzt noch kein Verbrechen im Zorn begangen: erst die unglückliche Liebe wütet wahrhaftig"), bezieht infelix amor richtig auf die Besessenheit der einstmals in Jason verliebten Medea und erklärt saevit als perfektisches Praesens, was nach fudi und feci nicht gerade leicht fällt. Um das geforderte Perfekt zu erhalten, muß man aber gar nicht ändern (suasit Peiper, movit Leo, fecit Garrod; ein Perfekt erstrebt auch Most mit seiner Herstellung saeviit felix amor), sondern nur die Überlieferung im Sinne eines Perfekts sevit von serere ausdeuten. Vgl. 
Phaed. 494 scelera populos inter atque urbes sata; Verg. Aen. 7.339 sere crimina belli (wo crimina auch „Vorwürfe” heißen kann).

Med. 447-453

Fugimus, Iason, fugimus - hoc non est novum,

Mutare sedes; causa fugiendi nova est:

Pro te solebam fugere - discedo, exeo,

450 Penatibus profugere quam cogis tuis.

Ad quos remittis? Phasin et Colchos petam

Patriumque regnum quaeque fraternus cruor

Perfudit arva? quas peti terras iubes?

Die durch causa fugiendi nova est angekündigte scharfe Antithese zwischen Pro te ... fugere und Penatibus profugere ... tuis (deutlich forciert durch die Wahl des Kompositums profugere) läßt es nicht zu, daß das zweite Glied (Penatibus profugere ... tuis) in einem Relativsatz mit ungewöhnlich weit nachgestelltem Relativpronomen nachhinkt, wie es in der Überlieferung der Fall ist. Zudem kommen discedo und exeo erst recht zur Geltung, wenn der Begriff penatibus vorausgegangen ist. Ich erwäge:

Fugimus, Iason, fugimus - hoc non est novum,

Mutare sedes; causa fugiendi nova est:

Pro te solebam fugere - iam cogis tuis

450 Penatibus profugere: discedo, exeo-

Ad quos remittis? ...

Mit dem hergestellten iam cogis erhält solebam sein natürliches Gegenglied zurück. Auf den von Jason ausgeübten Zwang reagiert Medea mit dem freimütigen Zugeständnis discedo, exeo. Dem durch die beiden Komposita forcierten Aspekt des Weggehens setzt sie dann in V. 451 die Frage „Aber wohin?” entgegen, wo man die asyndetische Antithese vielleicht durch Leos $A t$ quo remittis nachschärfen wird (für das überlieferte $A d$ quos plädiert Zwierlein LP I 214 Anm. 51).

Die Vertauschung der beiden Halbverse liegt sehr nahe, sobald einmal Textausfall durch Augensprung von fugere zu profugere erfolgt ist und man die am Rand nachgetragenen Worte iam cogis tuis/ Penatibus profugere fälschlich zu einem einzigen Vers zusammensetzte. Zu einer ähnlichen Korruptel (Vertauschung zweier Halbverse und eine kleine zusätzliche Folgeverderbnis) vgl. Zwierleins überzeugende Gestaltung von Med. 22 f. nach Leo und Axelson.

Med. 465-476

... ingratum caput,

Revolvat animus igneos tauri halitus

Interque saevos gentis indomitae metus

Armifero in arvo flammeum Aeetae pecus,

Hostisque subiti tela, cum iussu meo

470 Terrigena miles mutua caede occidit;

Adice expetita spolia Phrixei arietis 


\section{Somnoque iussum lumina ignoto dare \\ Insomne monstrum, traditum fratrem neci \\ Et scelere in uno non semel factum scelus, \\ 475 Ausasque natas fraude deceptas mea \\ Secare membra non revicturi senis.}

Die Partie wird maßgebend bestimmt durch Reminiszenzen an Ovid, der die entsprechenden Abenteuer Medeas mehrfach geschildert hat (vgl. Jakobi 1988: 54 f.). Jedoch enthält ein Glied der Aufzählung, nämlich die Einholung des Goldenen Vließes (471) eine von den Kommentaren bislang nicht beobachtete Reminiszenz an das ennianische Vorgängerwerk. Die Medea des Ennius beginnt mit den folgenden Worten der Amme (208-216 Jocelyn):

Utinam ne in nemore Pelio securibus

Caesa accidisset abiegna ad terram trabes,

210 Neve inde navis incohandi exordium

Cepisset, quae nunc nominatur nomine

Argo, quia Argivi in ea delecti viri

Vecti petebant pellem inauratam arietis

Colchis imperio regis Peliae per dolum.

215 Nam numquam era errans mea domo ecferret pedem

Medea, animo aegra, amore saevo saucia.

Die Verschleifung des wahrscheinlich nach klassischer Praxis mit konsonantischem - $i$ - dreisilbig zu messenden Schlußwortes arietis (vgl. Strzelecki 1938: 52 f.: Mit dieser Auffassung wird die Annahme einer - bei Seneca seltenen - aufgelösten fünften Hebung umgangen) mit dem Attribut Phrixei muß einen aufmerksamen Leser an den sechsten Vers der ennianischen Medea erinnern:

Adice expetita spolia Phrixei arietis

Vecti petebant pellem inauratam arietis.

Es wäre denkbar, die metrischen Entsprechungen noch zu verstärken durch die Herstellung von Vecti $<$ ex>petebant, welche ennianischem Sprachgebrauch durchaus entspräche (vgl. fr. 350 Jocelyn Unde sibi populi et reges consilium expetunt). Entscheidend gegen diese Erwägung spricht indes die von Ennius sicher erstrebte Alliteration petebant pellem.

Wenn man die Reminiszenz erst erkannt hat, ist die sich in ihr bekundende intertextuelle Aussagetendenz mit Händen zu greifen: Mit einer einzigen von vielen für Jason erbrachten Leistungen hat Medea die von den Argonauten unternommene Expedition zu einem Erfolg geführt. Natürlich ist das expetere bei Seneca in einem vergleichsweise gegenüber dem ennianischen petere verengten Sinne gebraucht: Es bezieht sich nur auf den "einholenden" Gang in den Hain, bei welchem die bewachende Schlange überwunden werden mußte, nicht etwa auf die ganze gefährliche Seereise, mittels derer das Goldene Vließ nach Griechenland "geholt” werden sollte. Und doch war es letztlich Medea, die mit diesem erfolgreichen Gang die gesamte Überseeexpedition hat gelingen lassen. Der negativen Perspektive der Amme, welche die Argonautenfahrt als eine Medea mit ins Unglück reißende Schreckensunternehmung darstellt, 
wird die positive Sichtweise der Medea selbst gegenübergestellt, die das letztliche Gelingen dieser Unternehmung als ihre Leistung betrachtet.

Med. 515-519

IA Quid facere possim, loquere. ME Pro me vel scelus.

IA Hinc rex et illinc - ME Est et his maior metus

Medea. nos tconfligere. certemus sine,

Sit pretium Iason. IA Cedo defessus malis.

Et ipsa casus saepe iam expertos time.

Avantius schrieb conflige[re] (empfohlen jetzt auch von Fitch 2004a: 90), was Delz zu compone variiert. Axelson (vgl. Zwierlein KK 149, anders LP I 179) sieht dagegen confligere als Glossem an, welches etwa einen Vokativ marite verdrängt habe. Die weiteren Vorschläge sind Legion.

Auffälligerweise hat man bislang nicht berücksichtigt, daß Jason auf seine Bedrängnis durch zwei Könige (Acastus und Creon) verweist. Diesen Gedanken sollte auch Medea in ihrem Angebot berücksichtigen, so daß ein nos utrique certemus sine naheläge (certare mit Dativ etwa in HO 1807). Für diese Lösung spräche sowohl der entsprechende Ausdruck in 522 Utrumque profuge als auch die Fortführung der rhetorischen Kumulation der Feinde durch Medea in 527 f. (adice, iunge). Graphisch wäre ein abbreviiertes confligere einem utrique nicht unähnlich, obwohl confligere vielleicht eher einer Glosse entstammen könnte.

Med. $777 \mathrm{f}$.

Oetaeus isto cinere defecit rogus,

Qui virus Herculeum bibit.

V. 777 bedeutet „to these ashes collapsed the pyre on Oeta" (Costa). Aber den Gedanken des Zusammensinkens sähe man gern durch ein pittoreskeres Wort ausgedrückt als das abstrakte defecit, welches offenbar den Gesichtspunkt des nachlassenden Brennens fokussiert. Ein Verb mit der wörtlichen Bedeutung „niedersinken” könnte auch den resultativen Ablativ isto cinere besser regieren als defecit. Der Vergleich mit Stat. silv. 5.3.199 f. Vix requies flammae necdum rogus ille deorum/ Siderat (Imitation unserer Stelle?) empfiehlt die Herstellung des preziösen desedit für defecit, ein Wort, welches zwar im Tragödiencorpus fehlt, aber mehrfach in Senecas Naturales quaestiones begegnet $(1.14 .1 ; 3.27 .6 ; 4 b .10 .1 ; 6.6 .4)$.

Med. 954-957

Utinam superbae turba Tantalidos meo

955 Exisset utero bisque septenos parens

Natos tulissem! sterilis in poenas fui:

Fratri patrique quod sat est, peperi duos. 
Insofern hier - anders als in Thy. 895 quod sat est, videat pater - der quantitative Aspekt im Mittelpunkt steht, wird man die Herstellung von quot für quod erwägen. Zur Ellipse von me genuisse bei unpersönlichem sat est vgl. Sil. Pun. 7.62 f. supersunt, I Quot tibi sit Libyaeque satis und Priap. 77.11 Poenas do quoque, quot satis superque est.

Phaed. 687-693

O scelere vincens omne femineum genus,

O maius ausa matre monstrifera malum

Genetrice peior! illa se tantum stupro

690 Contaminavit, et tamen tacitum diu

Crimen biformi partus exhibuit nota,

Scelusque matris arguit vultu truci

Ambiguus infans - ille te venter tulit.

Zwierlein KK 201 f. verteidigt den von Bothe getilgten V. 688 (Damsté versetzte ihn hinter V. 693) durch Hinweis auf die „im Zusammenhang besonders sinnvolle” Junktur matre monstrifera und die vierfache m-Alliteration; er akzeptiert die den Anlaß zur Tilgung gebende Redundanz maius ... matre .../ Genetrice peior.

Bothe selbst hatte wohl schon ähnliche Bedenken gegen seine eigene Tilgung: Er erwog in seinem Apparat, das preziöse Attribut monstrifer (hier zuerst, dann bei Lucan und Valerius Flaccus) zu retten durch ein omne monstriferum genus am Ende des verbleibenden V. 687.

Mit diesem Vorschlag dürfte Bothe einer befriedigenden Lösung den Weg gebahnt haben. Es erscheint schwer denkbar, daß Hippolytus, wenn er Phaedra zunächst als Vertreter der ihm im allgemeinen verhaßten Frauen beschimpft (V. 687 in seiner überlieferten Fassung) und schließlich auf ihre Mutter Pasiphae rekurriert (V. 689), es verabsäumen sollte, dazwischen auf die erotisch verruchte Familie der Sol-Nachfahrinnen zu sprechen zu kommen. Demnach wird man den von Bothe in V. 687 gesuchten Gedanken in den von ihm wohl zu Unrecht getilgten V. $688 \mathrm{zu}$ verlegen suchen.

Dies läßt sich erreichen, indem man dort matre (Glossem zu Genetrice?) in gente ändert. Die Junktur gens monstrifera in bezug auf die an monstra reiche Familie der Phaedra scheint zumindest nicht weniger passend als monstrifera mater in bezug auf Pasiphae, die nur den einen Minotaurus geboren hat. Der Gesamt Ausdruck O maius ausa gente monstrifera malum, der Pasiphae ein Verbrechen begehen läßt, welches selbst über die Maßstäbe ihrer an monstra reichen Familie hinausgeht, wirkt sprachlich anspruchsvoller als die einen schlichten Vergleich zwischen zwei Personen enthaltende Überlieferung $O$ maius ausa matre monstrifera malum. Schließlich läßt sich der von Zwierlein hervorgehobenen Alliteration (die durch die Herstellung von gente ein Glied einbüßt), die paronomasieartige Assonanz entgegenhalten, welche die in kunstvoller Weise sukkzessive abnehmenden und sich sachlich zuspitzenden Glieder omne femineum genus, gens monstrifera und genetrix zusammenhält. 
Phaed. 1207-1210

Tuque semper, genitor, irae facilis assensor meae:

Morte facili dignus haud sum qui nova natum nece

Segregem sparsi per agros quique, dum falsum nefas

1210 Exsequor vindex severus, incidi in verum scelus.

Zwierlein LP I 292 f. weist zurecht die Versuche Früherer, V. 1207 zu versetzen oder syntaktisch mit den vorausgehenden Worten zusammenzunehmen, zurück. Doch sein eigener Vorschlag, nach V. 1207 den Ausfall eines Verses anzunehmen (e.g. <Nunc quoque adsis atque nato dira supplicia ingere>), dürfte an der auffälligen Korrespondenz zwischen facilis assensor und Morte facili (beseitigt durch Withof, der am Anfang von V. 1208 Morte quali dignus heu schreibt) scheitern und ein kunstvolles Anakoluth beseitigen: Die Anrede in V. 1207 war ursprünglich auf eine Aufforderung der Art nunc quoque me, mihi ipsi irascentem, facile occide angelegt, doch der in facile occide liegende Gedanke einer mors facilis bestimmt Theseus zum Ausscheren aus der Konstruktion: „Und du, mein Vater, der Du stets leicht meinem Zorne beistimmst - nein, einen leichten Tod verdiene ich wirklich nicht". Etwas anders verteidigt Fitch (2004a: 132) die überlieferte Versfolge.

Oed. 233-238

Mitia Cadmeis remeabunt sidera Thebis,

Si profugus Dircen Ismenida liquerit hospes

235 Regis caede nocens, Phoebo iam notus et infans.

Nec tibi longa manent sceleratae gaudia caedis:

Tecum bella geres, natis quoque bella relinques,

Turpis maternos iterum revolutus in ortus.

Heinsius änderte Turpis in ein zu bella gehöriges Turpia (Stupro schreibt dagegen jetzt Giardina). Aber das prädikative Turpis hat seinen guten Sinn als Fortführung von Nec tibi longa manent sceleratae gaudia caedis: Die Schande des Inzests wird als Strafe für den frevelhaften Vatermord dargestellt. Dieses Verhältnis tritt aber erst klar hervor, wenn man V. 238 hinter V. 236 versetzt (Farnabius wollte V. 238 hinter V. 235 versetzen, also an die Worte Phoebo iam notus et infans anschließen, wo er vor Nec tibi longa manent sceleratae gaudia caedis zu früh käme). Der Kampf mit sich selbst (V. 237), der wohl der Selbstblendung entspricht, ist wiederum eine Folge der sich im Inzest bekundenden widernatürlichen Reflexivität (V. 238), und der an die Söhne vererbte widernatürliche Krieg schließt die Prophezeiung in natürlicher Weise ab.

Oed. 384-389

OE Quid ista sacri signa terrifici ferant,

385 Exprome; voces aure non timida hauriam:

Solent suprema facere securos mala.

TI His invidebis quibus opem quaeris malis. 
OE Memora quod unum scire caelicolae volunt,

Contaminarit rege quis caeso manus.

Töchterle z.St. mustert die verschiedenen Versuche durch, V. 388 zu erklären, der in seiner überlieferten Form den Eindruck zu vermitteln scheint, „,als ob auch die Götter den Täter bisher nicht kennen": Morel eliminierte die Götter, indem er ein sonst nicht bezeugtes Thebicolae für caelicolae schrieb, Delz änderte scire in eruere, wogegen Töchterle zurecht einwendet, daß man eher das Passiv erwarte. Mit der Überlieferung begnügten sich G. Müller, der zu volunt einen Subjektsakkusativ me bzw. nos „suppliert” und Axelson, der unum (sc. me) als diesen Subjektsakkusativ ausdeutet.

Im Zusammenhang der mantischen Szene wird man die caelicolae als die Inhaber des Oedipus vorenthaltenen Wissens ansehen müssen; insofern wird Oedipus kaum von ihnen sagen, daß sie es wünschten, daß er den Täter kenne, sondern vielmehr, daß sie ihn an ihrem Wissen nicht teilhaben lassen. Im Zuge der Orakeldeutungen des Tiresias hat Oedipus eine Fülle diffuser Schreckzeichen erhalten, aber eben keine Antwort auf seine kriminalistische Frage. Insofern wird er in seiner Ungeduld Tiresias auffordern, endlich das zu sagen, was ihn die Götter als einziges nicht wissen lassen (hyperbolische Übertreibung): Memora quod unum scire caelicolae vetant (valent schreibt jetzt Giardina). Sachlich vgl. 331-333 Solet ira certis numinum ostendi notis:/ Quid istud est quod esse prolatum volunt/ Iterumque nolunt et truces iras tegunt?. vetare (gegen die klassische Prosaregel) ohne ausgesprochenes persönliches Akkusativobjekt mit aktivem Infinitiv auch Tro. 291 Qui non vetat peccare, cum possit, iubet.

Oed. 957-962

... dixit atque ira furit:
Ardent minaces igne truculento genae
Oculique vix se sedibus retinent suis;
960 Violentus audax vultus, iratus ferox
Iamiam eruentis; gemuit et dirum fremens
Manus in ora torsit ...

Während Frühere eruentis durch ein anderes Partizip ersetzten, welches sich mit dem überlieferten Tantum verbindet (struentis Cornelissen, furentis oder minantis oder voventis Richter), behalten die Jüngeren eruentis bei (was ja im Zusammenhang der Selbstblendung vorzüglich paßt) und suchen Tantum zu verbessern: Sluiter schreibt Iamiam (aufgenommen von Zwierlein und gebilligt von Fitch 2004a: 153), neben dem man jedoch lieber ein Partizip Futur sähe, Delz Tandem, was ein wohl zu starkes Engagement des Boten impliziert. Schließlich verteidigt Töchterle Tantum im Sinne von dummodo (was nicht seiner Übersetzung entspricht: „zerstörerisch, verwegen das Gesicht, erzürnt und wild, nur noch auf das Herausreißen bedacht"), erwägt aber auch eine Abänderung von eruentis in das Gerundivum eruendus. Inwiefern sich dieses (doch nur passiv zu verstehende) Gerundiv „dem Kontext der „aktiven” Augen entsprechend anfügt", bleibt rätselhaft. Nachzutragen noch der Versuch Giardinas (Saevum tuentis), der mit einer zweifachen Änderung lahmen Sinn erkauft. 
Vorzuziehen ist solchen Versuchen wohl ein paradox-zynisches Wortspiel mit der Doppelbedeutung von vultus (einerseits "Gesichtsausdruck”, andererseits "Augen”, zu letzterem vgl. etwa 1012 Vacuosque vultus und Phoen. 43 Foditque vultus):

Violentus audax vultus iratus ferox

Vultum eruentis ...

$\mathrm{Zu}$ ähnlichen polyptotischen Ausdrücken vgl. Herc. $250 \mathrm{f}$. Sensere te r r a e pacis auctorem suael Abesse terris; $1167 \mathrm{f}$. hos tis est quisquis mihil Non monstrat ho ste m; Tro. 233 Et tanta gessit bella, dum bellum parat; 869 Optanda mors est sine metu mort is mori; Thy. 572 Peior est bello timor ipse belli; 994 noxque se in noctem abdidit.

Oed. 1014-1018

1015 Haut est nefandos. dividat vastum mare

... congredi fas amplius

Dirimatque tellus abdita et quisquis sub hoc

In alia versus sidera ac solem avium

Dependet orbis alterum ex nobis ferat.

Töchterle ergänzt zu Dirimatque tellus abdita als Objekt aus V. 1018 alterum (als ob dirimere nicht natürlicherweise ein pluralisches Objekt erheische) bzw. will tellus abdita als den „Wohnort nach dem Ergebnis der Trennung” verstehen.

Beides erscheint sprachlich schwer vorstellbar. Eher sollte man annehmen, daß die Erde als trennende Instanz zum vastum mare hinzukommt und daß die Trennung durch Meer und Erde dann noch durch die Antipodenvorstellung übersteigert wird. Dann hätte man einfach abdita in addita zu ändern.

Oed. 1024-1031

Quid, anime, torpes? socia cur scelerum dare

1025 Poenas recusas? omne confusum perit,

Incesta, per te iuris humani decus:

Morere et nefastum spiritum ferro exige.

Non si ipse mundum concitans divum sator

Corusca saeva tela iaculetur manu,

1030 Umquam rependam sceleribus poenas pares

Mater nefanda ...

Töchterle wehrt sich zurecht aus sprachlichen Gründen dagegen, concitans prädikativ im Sinne von quatiens aufzufassen, und will das Partizip nur attributiv im Sinne der „Dynamis des Zeus, mit der er die Welt in Bewegung hält,” verstehen.

Wenn Jokaste jedoch tatsächlich äußerte „nicht einmal wenn mich Jupiter durch Blitzschläge tötete, könnte ich jemals angemessene Strafe zahlen", so würde damit wohl viel zu wenig gesagt, und Töchterle hätte noch untertrieben, wenn er in der vorliegenen Gestaltung nur „das dürre Schema” derjenigen Selbstverwünschung sieht, die er zurecht am eindruchsvollsten bei Sen. Thy. 1077 ff. ausgeprägt findet: Dort bittet 
Thyest den Göttervater um den ganzen Kosmos verbrennende Blitzschläge, die am Schluß auch ihn selbst vernichten sollen (1089 ff.).

Im Sinne dieser pathetischen kosmischen Topik muß sich auch Jokaste geäußert haben; daß sich die Blitzschläge nicht nur gegen sie persönlich richten sollen, ist genaugenommen bereits in dem Plural tela (V. 1029) angelegt. Man wird mundum concitans einfach in mundum concremans ändern (zum Vorkommen des Kompositums vgl. Sen. Phoen. 346 und Phaed. 1216).

Ag. 193-202

Scelus occupandum est; pigra, quem expectas diem?

Pelopia Phrygiae sceptra dum teneant nurus?

195 An te morantur virgines viduae domi

Patrique Orestes similis? horum te mala

Ventura moveant, turbo quis rerum imminet.

Quid, misera, cessas? [en adest gnatis tuis

Furens noverca] per tuum, si aliter nequit,

200 Latus exigatur ensis et perimat duos;

Misce cruorem, perde pereundo virum:

Mors misera non est commori cum quo velis.

Die Verse 198 b/ 199 a, die Zwierlein im Anschluß an Axelson tilgt, scheinen einer Verteidigung fähig. Zwierlein (KK 265 f.) erklärt die Interpolation dadurch, daß man horum .../ ... turbo quis rerum imminet anstatt auf Clytemestra und Aegisth fälschlich auf die Kinder bezogen habe, welche Clytemestra tatsächlich nur als potentielle Rächer des Vaters ansehe.

Insofern sich Zwierlein für dieses Verhältnis der Clytemestra zu ihren Kindern aber nur aus Stellen aus dem Schlußteil des Dramas berufen kann, spricht nichts dagegen, daß sich Clytemestra in ihrem Entscheidungsmonolog doch momentan vernünftigerweise auf ihre Verantwortung für ihre Kinder besinnt (man vergleiche nur die Schwankungen, denen Medeas Verhältnis zu ihren Kindern unterliegt). Wenn man die Stimmungsumschwünge mit Gedankenstrichen markiert, kann man den Text folgendermaßen gestalten:

195 An te morantur virgines viduae domi

Patrique Orestes similis? - horum te mala

Ventura moveant, turbo quis rerum imminet. -

Quid, misera, cessas? en adest gnatis tuis

Furens noverca...

Der Verweis auf den unverheirateten Status ihrer Töchter muß man in Anbetracht der Geschehnisse um Iphigenie (die unter Vorspiegelung einer Ehe mit Achill nach Aulis gelockt wurde, vgl. 157 ff., wo die Amme das Argument der soboles Clytemestra als ernsthaften Hinderungsgrund vorhält und Clytemestra dieses Argument ironisch ablehnt) ebenso wie das Motiv der Ähnlichkeit zwischen Orest und dem ehebrecherischen Agamemnon als pure Ironie ansehen (hierzu vgl. Med. 24; die Ironie knüpft an die höhnische Selbstaufforderung zum Warten in V. 193 f. an). Mit diesen „Argumenten” 
kann sich Clytemestra nur zum Gattenmord anstacheln (anders Tarrant z.St. und Fitch 2004a: 157, die beide - freilich in unterschiedlicher Weise - den Rekurs auf die virgines und Orest in Vv. 195 f. als ernstgemeintes Gegenargument gegen den Gattenmord auffassen).

Dann besinnt sich die Sprecherin jedoch auf den turbo rerum, in welchen sie ihre Kinder durch den Gattenmord stürzen wird (die dann natürlich ihren Status als Königskinder verlieren und vor allem als potentielle Rächer angesehen werden). Den Ausschlag gegen diese vernünftige Besinnung (die sich auf die Verse 196 b/ 197 beschränkt) gibt dann ein gegenläufiges Argument, welches sich ebenfalls auf die Interessen der Kinder konzentriert: Diesen droht in Cassandra eine "rasende Stiefmutter". Dieses neue Argument schlägt offenbar deshalb durch, weil die "rasende Stiefmutter" bereits vor der Tür steht (en adest), der turbo rerum im Falle des Gattenmords jedoch erst für die Zukunft droht (vgl. malal ven tu ra moveant und imminet). Der Zeitdruck, den Clytemestra beim letzten Umschwung auf sich selbst durch die Worte Quid, misera, cessas? ausübt, wird also expliziert durch das imminet übersteigernde en adest: Der turbo rerum infolge des Gattenmords droht den Kindern erst in einer unbestimmten Zukunft, die Stiefmutter aber ist bereits anwesend. Mithin darf en adest etc. nicht getilgt werden. Clytemestra vollzieht den Entscheidungsprozeß an der hier betrachteten Stelle konsequent und durchgehend (wie immer man auch die Stichhaltigkeit ihrer einzelnen Argumente bewerten mag) unter Berücksichtigung der Zukunft ihrer Kinder.

Ganz ähnlich entscheidet sich Medea zum Kindermord: Zunächst sollen die Kinder für die Zukunft unbeschadet bleiben (947 f. habeat incolumes pater,/ Dum et mater habeat), dann sorgt der Gedanke der unmittelbar bevorstehenden Trennung für den Umschwung (948 ff. urguet exilium ac fuga:/ I a m i a m meo rapientur avulsi e sinu,/ Flentes, gementes - osculis pereant patris,/ Periere matris). Diesem Argument entspricht an der hier besprochenen Stelle die unmittelbar bevorstehende Ankunft der Stiefmutter.

Ag. 207-219

Hunc fraude nunc conaris et furto aggredi?

Quem non Achilles ense violavit fero, Quamvis procacem torvus armasset manum,

210 Non melior Aiax morte decreta furens,

Non sola Danais Hector et bello mora,

Non tela Paridis certa, non Memnon niger,

Non Xanthus armis corpora immixta aggerens

Fluctusque Simois caede purpureos agens,

215 Non nivea proles Cycnus aequorei dei,

Non bellicoso Thressa cum Rheso phalanx,

Non picta pharetras et securigera manu

Peltata Amazon, hunc domi reducem paras

Mactare et aras caede maculare impia?

In V. 210 verbinden Tarrant z.St. und Zwierlein KK 266 f. zunächst melior Aiax morte decreta furens (Tarrant: „Ajax who was a better man once he had decided to die”). Allerdings befremdet dann das nachklappende furens, das ja eigentlich die frühere 
Handlungsstufe bezeichnet. Nicht ganz entsprechend ist in dieser Hinsicht der von Zwierlein verglichene quamvis-Satz im Achill-Glied (V. 209).

Watts Konjektur maior statt melior (so jetzt auch Giardina) bedeutet sicherlich eine Trivialisierung. In LP I 322 entwickelt Zwierlein jetzt eine neue Deutung, derzufolge morte decreta furens zusammengenommen, melior „(den Atriden) im Kampf überlegen” heißen und morte decreta soviel wie caede (sc. Atridarum) decreta (was Fitch 2004a: 158 herzustellen erwägt) bedeuten soll, was aber sprachlich wohl zu obskur ausgedrückt wäre (vgl. auch Phaed. 258, wo Decreta mors est den Selbstmordplan der Phaedra bezeichnet).

Im wesentlichen zutreffen wird die ursprüngliche Deutung Zwierleins, welche derjenigen Tarrants entspricht: melior bezeichnet, daß Aiax durch den Selbstmordplan seine Ehre wiederherstellt. Es stört jedoch, wie gesagt, das nachklappende furens. Gegen eine erwogene Zusammennahme der Worte morte decreta furens richtet Tarrant das Argument „Ajax was no longer mad when he decided to kill himself” (Fitch 1.c. erwägt sogar, daß Seneca eine von der herkömmlichen abweichende Version des Aiax-Mythos vor Augen gehabt habe, gemäß welcher er im Wahnsinn Selbstmord begangen habe), aber ob diese rationalistische Einschätzung von Aiax' Selbstmord für einen Dichter der silbernen Latinität uneingeschränkt gilt, darf man im Lichte der Worte des lucanischen Selbstmörders Lentulus bezweifeln (Phars. 4.516 f.):

Proieci vitam, comites, totusque futurae

Mortis agor stimulis; furor est...

Demnach kann Seneca durchaus den Selbstmord des Aias als den „besseren Wahnsinn" auffassen, der ja die Ehre des Helden widerherstellt im Gegensatz zu seinem eigentlichen Wahnsinn, der diese befleckte. Ich erwäge die Herstellung des geschlossenen Ausdrucks Non melius Aiax morte decreta furens „nicht Aias, der durch seinen Selbstmordplan einem besseren Wahnsinn anheimfiel". Dann entspricht melius ... furens strukturell und in der Wortstellung exakt sola ... mora im folgenden Hector-Glied. Zur Korruptel vgl. Phoen. 612.

Ag. 544-556

Tandem occupata rupe furibundum intonat:

545 "Superasse +nunc pelagus atque ignes iuvat, Vicisse caelum Palladem fulmen mare.

Non me fugavit bellici terror dei,

[Et Hectorem una solus et Martem tuli]

Phoebea nec me tela pepulerunt gradu:

550 Cum Phrygibus istos vicimus - tene horream

Aliena inerti tela iaculantem manu?

Quid si ipse mittat?" plura cum auderet furens,

Tridente rupem subruit pulsam pater

Neptunus imis exerens undis caput

555 Solvitque montem; quem cadens secum tulit

Terraque et igne victus et pelago iacet. 
Zwierlein LP I 236 f. verteidigt die Verse 545 f. gegen Tarrants Tilgung durch die evidente Entsprechung zu V. 556 (in gleicher Richtung Fitch 2004a: 168). Genaue Betrachtung lehrt jedoch, daß durch diese Responsion nur V. 545 geschützt wird, wohingegen V. 546 mit einem hohen Maß an Wahrscheinlichkeit als Interpolation entlarvt wird. Denn das Paradoxe der Szene liegt ja gerade darin, daß der Meeresgott Aiax nicht einfach in seinem Element ertränkt, sondern den Fels, an den sich der dem Meer entkommene Aiax klammert, löst, also daß derjenige, der gerade noch prahlte, das Meer und das Feuer des Blitzschlags besiegt zu haben, jetzt durch die gemeinsame Einwirkung von Erde, Feuer und Meer zu Tode kommt. Die beiden Aufzählungsglieder pelagus und ignis werden also mit Bedacht in Hinsicht auf Solvitque montem durch das an die erste Stelle tretende Terraque als das ausschlaggebende Element erweitert (Aiax stirbt paradoxerweise, nachdem er das Land erreicht hat!). Diese Responsion zwischen V. 545 und V. 556 wird nun aber völlig verunklart durch die viergliedrige Aufzählung in V. 546, die an die Stelle einer klaren begrifflichen Scheidung der einzelnen Elemente eine hendiadyoinartige Auflösung setzt: Der Begriff „Blitzfeuer" scheint durch die drei Begriffe caelum Palladem fulmen umschrieben zu werden (Fitch 1.c. arbeitet die Verschiedenheit der Aufzählung in V. 546 gegenüber V. 545 heraus, um zu zeigen, daß keine nichtige Wiederholung vorliegt, berücksichtigt aber nicht die evidente Entsprechung zwischen V. 545 und V. 556). Es ist also keineswegs ausschließlich die nach Zwierlein a.a.O. nicht belegte lateinische „Ersatzform” Palladem, die V. 546 belastet. Im Gegenteil läßt sich V. 546, wenn man nur an V. 545 festhält, erst recht als eine den Zusammenhang störende Dublette entlarven.

Die Responsion zwischen V. 556 und V. 545 läßt es aber auch zweifelhaft erscheinen, ob Delzens (und Hudson-Williams') Einfügung eines Adjektivs saevum zu pelagus in V. 545 (Superasse saevum pelagus) die beste Lösung bietet (Zwierlein in einem Korrekturzusatz zu LP I 236). Zuvor favorisierte Zwierlein Richters Superasse cuncta, pelagus. Aber auch dieser Versuch ist nicht optimal, da ja der Schlußakkord der ganzen Episode in V. 556 gerade darauf hinausläuft, daß Aiax eben doch nicht „alles” besiegt hat. Gleichfalls unbefriedigend ist Axelsons Vorschlag Superasse numen pelagus, der ein neues Aufzählungsglied konjektural einfügt und somit die wohlbedachte Überbietung durch die Aufzählung in V. 556 zerstört. Passender erschiene ein prahlender Verweis auf die eigene Person, der dann durch Non me (547) und nec me (549) fortgeführt würde, em ehesten also Dürings bei Tarrant mitgeteilter Versuch Superasse me nunc pelagus (empohlen auch von Fitch 2004a: 167). Zu solcher genüßlicher Erweiterung des eigentlich allein hinreichenden und idiomatischen iuvat vgl. etwa Ov. ars 2.689 Me voces audire iuvat sua gaudia fassas. In Anbetracht der engen Entsprechung zu V. 556 darf man in V. 545 vielleicht sogar ignem statt ignes erwägen (es geht ja um das Element als solches, nicht um die einzelnen Blitzschläge).

Ag. 659-663

Cohibete lacrimas omne quas tempus petet,

660 Troades, et ipsae vestra lamentabili

Lugete gemitu funera: aerumnae meae

Socium recusant. cladibus questus meis

Removete: nostris ipsa sufficiam malis. 
Tarrant diagnostiziert richtig: „The entire passage 659-64 insists on a distinction between Cassandra's griefs and those of the chorus which the transmitted text of 659 fails to make".

Wenn der Sinn von V. 659 tatsächlich wäre „do not weep for Priam, since all ages to come will be eager to do so", so hätte sich Seneca mit petet (das Tarrant als lebhafteren Ausdruck anstatt e.g. dabit ansieht) recht eigenwillig ausgedrückt, indem er am Versende eine klare Antithese zu Cohibete (wie sie mit dabit leicht möglich gewesen wäre) vermieden hätte.

Heinsius' Konjektur omne quis tempus patet impliziert, wie Tarrant anhand von Phaed. 1244 zeigt, daß man jetzt besser etwas anderes tun als wehklagen sollte - was am geforderten Sinn vorbeigeht.

Tarrant selbst erwägt omne quae tempus petent oder petant, „weeping for Priam will engross all time to come; it should not be begun by those with other losses to mourn" (ähnlichen Sinn erstrebte wohl auch Bothe mit seinem Versuch omne quis tempus perit). Dies scheint jedoch in unpassender Weise zu implizieren, daß die individuellen Verluste der Angesprochenen in verhältnismäßig kurzer Zeit zu beklagen wären.

In allen Fällen scheitert der Versuch, den Gegenstand, welchen die Choreutinnen gemäß Cassandra nicht mehr beklagen sollen, durch die Junktur omne ... tempus eindeutig (und in Antithese zu den individuellen Verlusten der Einzelnen, ipsae vestra .../ ... funera) zu bestimmen. Am Ende des Chorlieds wurden die Stadtmauern Trojas (651 f.), die Tempel (653) und schließlich der König Priamos (655 ff.) beklagt. Insofern liegt es nahe, daß die Gegenstände der kollektiven Trauer den individuellen Verlusten entgegengesetzt werden, vgl. die (offenbar auf Imitation der vorliegenden Partie beruhende) ähnliche Passage HO 173-180:

At ego infelix non templa suis

Conlapsa deis sparsosve focos,

$175 \quad$ Natis mixtos arsisse patres

Hominique deos, templa sepulcris:

Nullum querimur commune malum.

Alio nostras fortuna vocat

Lacrimas, alias flere ruinas

180

Mea fata iubent.

Man wird die Korruptel eher in tempus als in den umstehenden Worten des Relativsatzes suchen. Ich erwäge Cohibete lacrimas, omne quas regnum petit „Laßt die Tränen, welche das (zerstörte) Reich als ganzes beansprucht". Nach der Korruptel von regnum in tempus bezog man Omne ... tempus in naheliegender Weise auf die Zukunft und änderte ursprüngliches petit (A) in petet (E).

Ag. 1001-1003

At ista poenas capite persolvet suo

Captiva coniunx, regii paelex tori.

Trahite, ut sequatur coniugem ereptum mihi.

In V. 1002 wird Cassandra als Captiva coniunx Agamemnons bezeichnet (von Giardina willkürlich in Captiva virgo geändert); Tarrant z.St. verweist auf den elegischen Gebrauch 
von coniunx im Sinne von paelex, aber man versteht trotzdem in der überlieferten Textfassung nicht recht, warum Clytemestra ihrer Nebenbuhlerin, bevor sie sie mit der vox propria, nämlich als paelex, bezeichnet, noch zu einer coniunx aufwertet.

In V. 1003 wird Agamemnon als der Clytemestra geraubte Ehemann (coniugem ereptum mihi) bezeichnet; Tarrant glaubt jedoch auch die Bedeutung "snatched from me by death" mitzuvernehmen, die sich indes im Munde der Mörderin höchst eigenartig ausnimmt. Wohl aus diesem Grund konjizierte Grotius coniugem ereptum sibi (sc. Cassandrae).

Der stilistische Sinn der parallelen Bezeichnung von Cassandra und Agamemnon durch das mit einem Attribut des "Geraubtseins" verbundene Substantive coniunx wird schlagartig deutlich, wenn man die Verse 1002 und 1003 versetzt:

At ista poenas capite persolvet suo.

Trahite, ut sequatur coniugem ereptum mihi

Captiva coniunx, regii paelex tori.

„Schleppt sie fort, damit sie, die kriegsgefange Gattin, ihrem mir geraubten Gatten folgt (sc. in den Tod)!"

Verächtlicher kann Cassandra das „Eheverhältnis” zwischen Cassandra und Agamemnon nicht zum Ausdruck bringen: Eine Kriegsgefangene verbindet sich mit einem einer anderen Frau entrissenen Mann. Zugleich klingt der Topos der "Gefangenen als Einnehmerin” an (vgl. 175 Amore captae captus; 191 Captae maritus ... et Priami gener). Variiert wird die Wendung ut sequatur coniugem .../ ... coniunx (mitsamt dem im Hintergrund stehenden Bezug auf die Hinrichtung) in Oct. $470 \mathrm{f}$. Invisa coniunx pereat et carum sibil Fratrem sequatur.

Thy. 13-20

In quod malum transcribor? o quisquis nova

Supplicia functis durus umbrarum arbiter

15 Disponis, addi si quid ad poenas potest

Quod ipse custos carceris diri horreat,

Quod maestus Acheron paveat, ad cuius metum

Nos quoque tremamus, quaere: iam nostra subit

E stirpe turba quae suum vincat genus

20

Ac me innocentem faciat et inausa audeat.

Den in V. 15 überlieferten Imperativ adde hat Gronovius zurecht beseitigt, indem er für adde ... potest (E : potes A) herstellt addi ... potest und so ein sich bis in V. 18 erstreckendes spannungsreiches Relativgefüge ermöglicht. Zweifeln muß man hingegen, ob Ascensius in V. 18 mit seiner allgemein akzeptierten Konjektur quaere für einhellig überliefertes quare das Richtige gefunden hat.

Vergegenwärtigen wir uns den Ablauf der Prologrede des Tantalus: Am Anfang wundert sich Tantalus, daß er vom gewohnten Ort seiner unterweltlichen Buße fortgeschleppt und wieder ins Diesseits gezerrt wird (1-4). Als Erklärungsmöglichkeiten für diesen ihm ungenehmen Ortswechsel erwägt Tantalus zunächst allgemein, daß eine grausamere Art der Bestrafung für ihn gefunden worden sei (4-6) und dann 
verschiedene mythologische Alternativstrafen (6-12). Er resümiert In quod malum transcribor? (13). Es steht also außer Zweifel, daß er annimmt, hinter seinem Ortswechsel stecke eine neue Form der Bestrafung.

Dann hebt eine Apostrophe an die zuständige Totengottheit an (13-15), innerhalb deren mit dem durch Gronovius (s.o.) restituierten weitausgreifenden Relativgefüge (15-18) erneut der Gedanke einer neuartigen, schlimmeren Strafe aufgegriffen wird.

Über diese neuartige Strafe (welcher Tantalus selbst ausgesetzt zu werden fürchtet) heißt es jetzt nach Ascensius' Konjektur quaere, als ob die Totengottheit diese Strafe erst noch suchen müßte (schon die Gedankenfolge o quisquis noval Supplicia .../ D is p o $n$ is .../ ... .../ ... quaere zeigt den Widerspruch: Die verteilende Gottheit wird die zu verteilenden neuen Strafen nicht erst suchen müssen). Die ganze vorgängige Gedankenführung zielte darauf ab, daß Tantalus dieser neuartigen Strafe zugeführt werden sollte. Mithin muß sie (gemäß der Vorstellung des Tantalus) längst gefunden sein. In Vv. 4-6 hieß es ausdrücklich peius inventum est sitil Arente in undis aliquid et peius famel Hiante semper?. Mithin verbietet sich die Herstellung von quaere in V. 18.

Es kommt hinzu, daß quaere einen logischen Anschluß der folgenden Worte unmöglich macht. Nach dem bisherigen Gedankengang müßte man quaere in dem Sinne verstehen, daß der Totengott eine neue Strafe für Tantalus suchen soll. Hieran schlösse sich der Verweis auf die Nachkommenschaft des Tantalus völlig sinnlos an.

Diejenigen Herausgeber, die nach quaere einen Doppelpunkt setzten, verstehen quaere offenbar im Lichte des Folgenden, also in dem Sinne „suche für meine Nachfahren!". Dies wäre an sich möglich, freilich wird mit dieser Deutung jeglicher Anschluß an In quod malum transcribor? und an die Reflexionen des Tantalus über den Zweck seiner Ortsveränderung unmöglich gemacht. Man müßte dann hinter In quod malum transcribor? geradezu ein Absatzende setzen und mit o quisquis einen völlig neuen Gedanken beginnen lassen.

Dieses logische Auseinanderklaffen zweier Prologteile, eines auf Tantalos und eines auf seine Nachfahren bezüglichen, läßt sich indes vermeiden, wenn man in V. 18 quare nicht mit Ascensius in quaere, sondern in parce korrigiert: Tantalos fordert den Totengott auf, ihn von der neuen Bestrafungsart, der er zugeführt zu werden fürchtet, $\mathrm{zu}$ verschonen bzw. diese für seine Nachkommen aufzusparen (parce kann gleichermaßen „verschone mich" wie "spar es auf” bedeuten), vgl. am Ende des Stücks das Schuldbekenntnis Thyests (1010 ff. Non tota ab imo tecta convellens solo/ Vertis [sc. Tellus] Mycenas? stare circa Tantalum/ Uterque iam debuimus: hinc compagibus/ Et hinc revulsis, si quid infra Tartara est/ Avosque nostros, hoc tuam immani sinu/ Demitte vallem, nosque defossos tegel Acheronte toto). Hieran schließt sich der Verweis auf die bereits nachdrängenden Nachkommen (iam nostra subit/ E stirpe turba) konsequent an. Tantalus bittet: „Wenn es eine neuartige, schlimmere Form der Strafe gibt, so verschone mich davon: Meine Nachfahren sind nicht fern."

Entfernt vergleichbar ist Oct. 618, wo sich der Totenschatten der Agrippina gegen eine bedrängende Erscheinung ihres ermordeten Ehegatten wehrt mit Verweis auf das bevorstehende "Nachrücken” Neros: Iam par ce: dabitur (sc. auctor necis), tempus haud longum peto. 
Thy. 40-48

$40 \quad$ Fratrem expavescat frater et gnatum parens

Gnatusque patrem; liberi pereant male,

Peius tamen nascantur; immineat viro

Infesta coniunx: bella trans pontum vehant,

Effusus omnis irriget terras cruor,

45 Supraque magnos gentium exultet duces

Libido victrix; impia stuprum in domo

Levissimum sit facinus: et fas et fides

Iusque omne pereat ...

Zwierlein, der in KK 294 die in Vv. 46 f. überlieferte Junktur stuprum ... . .. fratris (facinus coni. Bentley) noch im Anschluß an Axelson auf Thyests Verführung seiner Schwägerin bezog, zeigt in LP I 323-325 anhand einer eingehenden Analyse des Gedankengangs, daß es seit immineat (42) nurmehr um die Generation des Agamemnon geht, daß also ein Bezug des überlieferten stuprum .../ ... fratris auf die Verwicklungen zwischen Atreus und Thyest nicht möglich ist. Fitch (2004b: 251 f.) sucht diesen Bezug neuerdings zu erzwingen, indem er $46 \mathrm{~b}-48$ a (impia .../ ... ... pereat) hinter Infesta coniunx (43) versetzt. Dieser Eingriff bringt freilich den erheblichen Nachteil mit sich, daß sich die Anspielung auf die Flucht der Sonne (48 f.) nicht mehr an den resümierenden Gedanken des Verfalls von fas, fides und ius anschließt (47 f.), sondern an die Libido victrix (46).

Fraglich erscheint allerdings, ob man aus Zwierleins Analyse des Gedankengangs der überlieferten Versfolge die Schlußfolgerung ziehen muß, sich der Konjektur Bentleys anzuschließen. Ein facinus als substantivische Erweiterung des Prädikatsnomen Levissimum (Vilissimum jetzt willkürlich Giardina) ist ja keineswegs zwingend gefordert, und insofern leistet Bentleys Konjektur nicht mehr, als das unmögliche Genitivattribut fratris zu stuprum in eine nicht störende Erweiterung des Prädikatsnomens zu verwandeln.

Indes scheint als Subjekt der Periode impia ... in domo/ Levissimum sit ... eine bestimmte Untat eines bestimmten Familienmitglieds recht passend. Man sollte also aus Zwierleins treffender Analyse der konkreten mythologischen Bezüge der Anspielungen eher die Konsequenz ziehen, das überlieferte fratris in matris (sc. Clytemestrae) zu verwandeln. Generell ist nach römischer Moralvorstellung die mater familias diejenige Person, die sich am wenigsten Unzucht zuschulden kommen lassen sollte. Insofern entbehrt die Aussage impia stuprum in domo/ Levissimum sit matris nicht einer paradoxen Schärfe, die der überlieferten Fassung mit stuprum .../ ... fratris dagegen völlig abgeht. Vor allem aber hat die hergestellte Junktur stuprum .../ ... matris den Vorzug, durch ihre beiden Bestandteile nachdrücklich auf die „weniger leichten” Verbrechen im Hause des Agamemnon zu verweisen: Der Begriff stuprum als Subjekt zu Levissimum sit impliziert deutlich, daß es zu Schlimmerem als bloßem stuprum, nämlich zum Gattenmord, kommen wird, und matris weist ebenso deutlich hin auf die spätere Vergeltungstat des Sohnes, den Muttermord Orests. 
Thy. 56-62

... Thracium fiat nefas

Maiore numero. dextra cur patrui vacat?

[Nondum Thyestes liberos deflet suos?]

Ecquando tollet? ignibus iam subditis

60 Spument aena, membra per partes eant

Discerpta, patrios polluat sanguis focos,

Epulae instruantur ...

Zwierlein KK 294-297 bezeichnet die Probleme des V. 58 präzise, die in der verfrühten Erwähnung von Thyestes' „Beweinen” (noch vor der mit tollet bezeichneten „Beseitigung” der Kinder, V. 59) bestehen und in der Tatsache, daß ein solches „Beweinen” im Schlußteil des Dramas faktisch nicht stattfindet. (Zumindest das Problem der Reihenfolge wird angegangen durch zwei Versetzungsversuche: Richter löst den problematischen V. 58 in die Halbverse liberos deflet suos/ Nondum Thyestes auf und versetzt diese hinter numero in V. 57, Hudson-Williams bevorzugt dagegen die Position hinter tollet in V. 59). Am Ende verteidigt Zwierlein V. 58 als „einen an die drängende Frage dextra cur patrui vacat? angeschlossenen weiteren Ausdruck der Ungeduld" und bezieht tollet als einen typisch zweideutigen Ausdruck auf die „Vertilgung” der Kinder durch Thyest.

In der OCT-Ausgabe dagegen schließt sich Zwierlein der Tilgung von V. 58 durch Tarrant an (vgl. LP I 325 und $330 \mathrm{f}$. Anm. 5), die es ermöglicht, tollet nicht (wie nach V. 58 kaum anders möglich) auf Thyest, sondern auf Atreus (patrui, V. 57) zu beziehen.

Gegen die sich nach der Tilgung ergebende Satzfolge „Warum ist seine Hand untätig? Wird er sie irgendwann erheben?" wendet sich wiederum Fitch (2004b: 252 f.) (a.) wegen des Subjektswechsels und (b.) weil tollet in diesem Zusammenhang (,,seine Hand erheben") seine Ambiguität verliert, die es in der überlieferten Satzfolge (mit Thyest als Subjekt) besitzt. Außerdem weist Fitch auf die Seltenheit des Interrogativums Ecquando hin, dessen Herstellung nach Ascensius (Et quando alle Handschriften) unter der Voraussetzung von Tarrants Tilgung unumgänglich ist.

Fitchs eigener Versuch beseitigt aber nicht die Schwierigkeiten von V. 58, sondern sucht nur der possessiven Wendung liberos ... suos eine besondere Pointe in Hinsicht auf das Subjekt des Satzes zu geben: Fitch betrachtet Thyestes als ein Glossem zu ursprünglichem Nondum stuprator oder Nondumne adulter. Die Anspielung darauf, daß es sich bei den vom stuprator bzw. adulter Thyest verspeisten Kindern (im Gegensatz zu Agamemnon und Menelaus) um seine unzweifelhaften Abkömmlinge handele, werde dann im folgenden Vers durch tollet fortgeführt, das sich in doppeldeutiger Weise auch auf die Anerkennung von Kindern beziehe.

Eine solche Anspielung scheint jedoch in einem Zusammenhang, wo es im Munde der Furie nur um den von Atreus initiierten Frevel gehen soll, höchst fragwürdig. Überdies geht Fitch auf die von Zwierlein markierten Schwierigkeiten des V. 58 in keiner Weise ein, dessen grundsätzlichen Sinn sein Eingriff (abgesehen von einer ihrerseits fraglichen zusätzlichen Pointe) unverändert läßt.

Wünschenswert wäre es aber in der Tat, wenn die Furie, der es ja nur um die Initiierung des Frevels durch Atreus (und nicht etwa um dessen Folgen, wie etwa des 
„Beweinen” des Thyest) gehen kann, bei der dextra ... patrui als Subjekt bliebe. Dies wäre der Fall in folgender Textfassung:

$$
\text { ... dextra cur patrui vacat? }
$$

Nondum Thyestae liberos defert suos -

Et quando tollet? ...

„Warum ist die Rechte des Onkels leer? Noch immer führt sie nicht dem Thyest seine eigenen Kinder zu - und wann endlich wird sie diese aufnehmen (bzw. beseitigen)? ..."

Dann ist bei vacat nicht das Umklammern des Schwertes (Zwierlein KK 295) gedacht, sondern an die im folgenden Vers thematisierte "Zuführung" der Kinder Thyests zu ihrem Vater; dafür ist mit defert (i.q. transfert) ein denkbar abstrakter, ja sogar gerade$\mathrm{zu}$ formalistisch wirkender Ausdruck gewählt, der in gewollt neutraler Weise den frevelhaften Akt umschreibt, daß Atreus dem Thyest seine eigenen Kinder zur Speise vorsetzt (zur Beziehung von suos i.q. „eigen” auf ein anderes Satzglied als das Subjekt vgl. Kühner \& Stegmann I 602 f. und in gleichem Kontext Thy. 890 f. pergam et implebo patrem/ Funere suorum und 979 Totumque turba iam sua implebo patrem; entsprechend hierzu hat deferre oft die Bedeutung „einem etwas wohlverdientermaßen zukommen lassen", vgl. etwa honorem deferre alicui). An die Aussage, daß die Rechte des Atreus noch nicht dem Thyest seine Kinder zuführt (vgl. Thy. 997 redde iam gnatos mihi!), schließt sich ganz passend die ungeduldige Frage an, wann endlich sie (die Rechte) diese (die Kinder) dann aufgreifen (bzw. vernichten) wird, und auch der kopulative Anschluß Et (sc. si nondum defert) quando tollet ist ohne Anstoß. Im Anschluß an defert wird man tollet zunächst in seinem "harmlosen” Sinne „aufheben” verstehen, wenngleich dem den Mythos überblickenden Leser die Bedeutung „vernichten” kaum entgehen wird.

Thy. 267-275

\author{
Nescioquid animus maius et solito amplius \\ Supraque fines moris humani tumet \\ Instatque pigris manibus - haud quid sit scio, \\ 270 Sed grande quiddam est. ita sit. hoc, anime, occupa \\ (Dignum est Thyeste facinus et dignum Atreo, \\ Quod uterque faciat): vidit infandas domus \\ Odrysia mensas - fateor, immane est scelus, \\ Sed occupatum: maius hoc aliquid dolor \\ 275 Inveniat...
}

In Vers 272 entscheidet sich Zwierlein, dessen Text hier reproduziert ist, für die Textfassung des Etruscus, gegenüber welcher in der A-Tradition das verseinleitende Relativpronomen Quod fehlt. Metrisch sind beide Lesarten gleichermaßen korrekt.

Im KK (p. 300) rechtfertigt Zwierlein seine Entscheidung: Er nimmt eine „etwas redundante Formulierung" in Kauf (die darin besteht, dass Dignum hier zugleich mit den Ablativen Thyeste bzw. Atreo und dem sinngleichen konsekutiven Relativsatz Quod uterque faciat verbunden wird): „Es geht nicht darum, dass beide Brüder an dem Verbrechen mitwirken („,ego interficiendo fratris natos, ille comedendo suos" kommentiert 
Farnabius; Heinsius 39 wollte deshalb uterque faciant schreiben), sondern dass es ein Verbrechen von der Art ist, wie es beiden Brüdern gut ansteht" (wozu Zwierlein auf die Worte des Atreus nach seiner Tat in 1104 ff. verweist).

Tarrant im Kommentar z.St. spricht sich dagegen für die A-Variante (ohne Quod) aus und verweist auf das Phänomen syntaktischer Interpolation in der E-Tradition. Er nimmt ebenfalls an, dass Atreus an die Möglichkeit denke, Thyest könne die von ihm ausgedachte Rache seinerseits ausführen, sucht diesen Gedanken aber mit der Deutung des Farnabius zu kombinieren: „Atreus' fear that Thyestes may be plotting against him finds an outlet in wit: the crime he is considering is one that both of them can - and must - commit, since Thyestes himself will play an essential part in it".

Fitch (2004a: 180 f.) entscheidet sich ebenfalls für Farnabius und die A-Fassung, die er mit dem Schluß von Atreus' Monolog stützt (285 f. Quod est in isto scelere praecipuum nefas, / Hoc ipse faciet sc. Thyestes). Allerdings minimalisiert Fitch den sachlichen Unterschied zwischen beiden Varianten (,The sense [in E] is much as in A, but A expresses it more stylishly"); dieses "Stilurteil” begründet er durch Senecas Vorliebe für parataktische Ausdrucksweisen und die Singularität der Doppelkonstruktion von dignus mit Ablativ und konsekutivem Relativsatz im Corpus der Senecatragödien.

Die Schwerfälligkeit dieser Doppelkonstruktion mag man in der Tat einem Stilisten wie Seneca nur ungern zumuten, zumal dann mit Quod uterque faciat lediglich derselbe Gedanke in deutlicher Formulierung aufgenommen würde, welcher mit Dignum est Thyeste facinus et dignum Atreo im Prinzip bereits - wenn auch in etwas weniger klarer Form - ausgesprochen worden ist.

Sachlich erhebt sich aber die Frage, ob der Gedanke „Thyest könnte das gleiche Verbrechen begehen", auch wenn dieser an anderen Stellen durchaus angemessen ist, gut paßt in einer Partie, in welcher sich Atreus einen völlig neuartigen und ungekannten Racheplan gegen seinen Bruder ausdenken will. Die Singularität dieser neuen Erfindung würde von vorneherein empfindlich geschwächt, wenn der Sprecher schon hier die Möglichkeit in den Raum stellte, sein verhaßter Bruder könne ebensogut wie er selbst auf diesen Plan verfallen.

Demnach wird die Interpretation des Farnabius, welche das Verbrechen gewissermaßen in die Aktivitäten von Atreus („interficiendo") und Thyest („,comedendo") zerlegt, zutreffen. Sie ist mit der E-Variante Quod uterque faciat schwerlich zu vereinbaren, da man einem Leser kaum zumuten kann, den konjunktivischen Relativsatz nach Dignum anders als im Sinne der normgrammatischen Konstruktion von dignus aufzufassen. Überdies würde gerade die in Farnabius' Deutung zentrale „Aufgabenteilung” nivelliert durch das in Quod (sc. facinus) gegebene, beiden Handelnden gemeinsame Objekt zu faciat.

Diese Schwierigkeit liegt aber auch in der A-Fassung, wenn man diese etwa mit Fitch in der neuen Loeb-Ausgabe folgendermaßen ausdeutet: „The deed is worthy of Thyestes and worthy of Atreus; let each perform it". Auf diese Weise wird facinus als Objekt zu faciat suppliert und somit der in Farnabius' Deutung zentrale Gedanke der "Aufgabenteilung" (wonach die beiden Brüder eben nicht dasselbe tun) verunklart.

Wenn demnach also die E-Lesart in der Tat offenbar auf syntaktischer Interpolation beruht, heißt dies andererseits noch nicht, dass die A-Variante, die ihrerseits wie Fitchs Deutung zeigt - den von Farnabius formulierten Gedanken noch nicht eindeutig herausbringt, ursprünglich sein muß. Im Gegenteil liegt es nahe, im Archetypos einen trivialen haplographischen Ausfall anzunehmen: 
Dignum est Thyeste facinus et dignum Atreo,

$<$ Ut $>$ uterque faciat ...

„Eine sowohl des Thyestes als auch des Atreus würdige Tat besteht erst darin, dass jeder von diesen beiden Täter ist (sc. und keiner von beiden ein bloßes Opfer) ..."

(Ut uterque faciat ist in scharf distinktiver Bedeutung gegenüber denkbarem $u t$ ambo faciant zu fassen - also wird man von Heinsius' Konjektur facia $<n>t$ unbedingt Abstand nehmen.)

Auf diese Weise wird mit einer geradezu etymologisierenden Wendung (est ... facinus/ Ut ... faciat) die Definition eines „,beider würdigen Verbrechens” gegeben. Mit dieser abstrakten Definition (die sich für einen den Mythos überschauenden Rezipienten natürlich trotz ihres höchst andeutungshaften Charakters erschließt) kommt der Leser bzw. Zuhörer dem Wesen von Atreus' Plan einen kleinen Schritt näher als durch die vorausgehenden mehrfachen Ankündigungen, es handele sich um eine alles Maß überschreitende Tat (252 ff.). Mit dieser Präzisierung wird zugleich die Ankündigung, Thyest als „Waffe” instrumentalisieren zu wollen (258 f. Quonam ergo telo tantus utetur dolor? - Ipso Thyeste), aufgegriffen, und dieselbe Gedankenkette („Thyest als handelnde Instanz innerhalb von Atreus' Racheplan") wird fortgeführt durch den bereits erwähnten Schluß der Rhesis mit den Worten Quod est in isto scelere praecipuum nefas,/ Hoc ipse faciet sc. Thyestes (285 f.), wo der Gedanke auf den - nunmehr als Täter isolierten - Thyest zugespitzt wird (vorbereitet schon durch $280 \mathrm{f}$. tam diu cur innocens/ Servatur Atreus?). Insofern sich die - in dieser Textform gegebene - Definition des „beider würdigen Verbrechens" also in die sukzessiv immer deutlicher werdende Beschreibung von Thyests Racheplan einfügt, sollte man sie keinesfalls (wie in der oben ausgeschriebenen Textfassung) als Parenthese aus dem Gedankenduktus aussondern.

In dieser Definition des „beider würdigen Verbrechens” läge zugleich die - gut zum Gesamtstück stimmende - rhetorische Pointe, dass zu Thyest genausowenig wie zu Atreus die Rolle des bloßen Opfers passt: Beide Figuren sind ihrer mythologischen Gesamtphysiognomie nach eben Täter, nicht Opfer.

Sprachlich ist zur Verwendung des $u t$-Satzes nach est mit dem Neutrum eines Abstraktums Kühner \& Stegmann II $244 \mathrm{f}$. zu vergleichen. Eine exakte Parallele bietet Cic. ND 2.71: cultus autem deorum est optumus idemque castissimus atque sanctissimus plenissimusque pietatis, ut eos semper pura integra incorrupta et mente et voce veneremur. Wie in der hier empfohlenen Textgestalt der Seneca-Partie hat das Abstraktum ein normativ wertendes Attribut (cultus ... optumus idemque castissimus atque sanctissimus plenissimusque pietatis vgl. Dignum ... Thyeste facinus et dignum Atreo), und das Prädikat des ut-Satzes nimmt den Inhalt des Abstraktums sachlich auf (facinus/ ut ... faciat bzw. cultus ... ut ... veneremur). Zur objektlosen Verwendung von facere vgl. im Tragödiencorpus Med. 987 perage (sc. vindictam), dum faciunt manus mit Zwierleins Kritischem Kommentar, p. 168, ferner ThLL VI 1, 120, 71 ff. und OLD s.v. facio 27 a (,to be active, take action").

Schließlich sei zur Art der Korruptel und zu der möglicherweise einer „Kakopho-

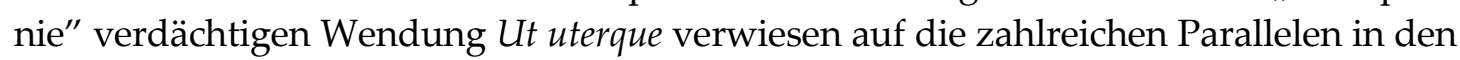
Ausführungen von Zwierlein LP I $208 \mathrm{f}$. zu Sen. Tro. 280, insbesondere auf die ganz entsprechende (aber bezüglich der Traditionszweige umgekehrte) Überlieferungssituation 
in Herc. 353 Ars prima regni est posse in invidia pati, wo statt Richters überzeugender Konjektur <in> invidia der Etruscus als haplographische Korruptel nur invidiam bietet, in der A-Tradition sich dagegen der notdürftige Verbesserungsversuch ad invidiam findet.

Thy. 1096-1102

... AT Nunc meas laudo manus,

Nunc parta vera est palma. perdideram scelus,

Nisi sic doleres. liberos nasci mihi

Nunc credo, castis nunc fidem reddi toris.

1100 TH Quid liberi meruere? AT Quod fuerant tui.

TH Natos parenti - AT Fateor, et, quod me iuvat,

Certos...

Einerseits wäre die Aussage liberos nasci mihil Nunc credo nur sinnvoll im Munde eines kinderlosen Sprechers, und andererseits ist das Attribut castis zu toris sowohl als Prolepse zur Bezeichnung einer phantastischen Rückgängigmachung des vollzogenen Ehebruchs (vgl. Tarrant z.St.) als auch als ironische Hervorhebung des tatsächlichen Zustands der Ehe höchst sonderbar. Beide Defekte verschwinden und man stärkt überdies die versgliedernde Funktion des anaphorischen nunc, wenn man schreibt ... liberos nasci mihi

Nunc credo certos, nunc fidem reddi toris.

Atreus wendet diesen ihm traumaartig ständig vorschwebenden Gedanken (vgl. schon $240 \mathrm{f}$. dubius sanguis et cert $i$ nihil/ Nisi frater hostis; $327 \mathrm{f}$. prolis incertae fides/ Ex hoc petatur scelere) konsequenterweise zunächst auf die eigenen Kinder, dann auf diejenigen Thyests (V. 1102) an.

HO 207-218

Vidi, vidi miseranda mei

Fata parentis

Cum letifero stipite pulsus

Tota iacuit sparsus in aula:

210 Pro, si tumulum fata dedissent,

Quotiens, genitor, quaerendus eras!

Potuine tuam spectare necem,

Nondum teneras vestite genas

Necdum forti sanguine, Toxeu?

215 Quid vestra queror fata, parentes,

Quos in tutum mors aequa tulit?

Mea me lacrimas fortuna rogat:

Iam iam dominae captiva colus

Fusosque legam. 
Das pluralische parentes in dem Sinne „Verwandte” gilt noch in der spätantiken Zeit des Hieronymus als Vulgarismus (Zwierlein KK 353). Daß Iole parentes in dem klassischen Sinne „Eltern” verwendet, also stillschweigend ihre Mutter mit einbezieht, mag man hinnehmen; sonderbar wäre dann freilich, daß der unmittelbar zuvor apostrophierte Bruder beiseitegelassen wird.

In Anbetracht von V. 208 ist das überlieferte parentes dringend eines Influenzfehlers verdächtig. Zwierlein bleibt in Hinsicht auf die „im Anapäst erstrebte Kongruenz zwischen syntaktischer und metrischer Einheit" skeptisch gegenüber Axelsons perennes, das prädikativ auf tulit im folgenden Vers zu beziehen wäre.

Offenbar liegt der Grund für Ioles Ablehnung einer weiteren Beklagung ihrer Angehörigen darin, daß deren Geschick im Gegensatz zu ihrem eigenen (V. 217 f.) durch den Tod endgültig abgeschlossen ist. Eine Möglichkeit wäre die Änderung von parentes in peracta. Vgl. hierzu Verg. Aen. 3.493 f. Vivite felices, quibus est fortuna peractal Iam sua: nos alia ex aliis in fata vocamur, wo fortuna peracta freilich nicht auf den Tod geht.

HO 380-390

380 Ut laeta silvas forma vernantes habet,

Quas nemore nudo primus investit tepor,

At cum solutos expulit Boreas Notos

Et saeva totas bruma decussit comas,

Deforme solis aspicis truncis nemus:

385 Sic nostra longum forma percurrens iter

Deperdit aliquid semper et fulget minus,

Nec illa venus est: quidquid in nobis fuit

Olim petitum cecidit et periit labans,

390 Aetas citato senior eripuit gradu

389 Materque multum rapuit ex illo mihi.

Vides ut altum famula non perdat decus?

Zwierleins Textkonstitution (die eng mit Axelsons Herstellung von V. 388 verbunden ist) führt zu der Härte, daß der Relativsatz quidquid in nobis fuit/ Olim petitum durch zwei sehr verschiedene Nachsätze aufgenommen wird, zunächst durch cecidit et periit labans (388), dann durch Aetas citato senior eripuit gradu (390); Leo, der die Vv. 389 und 390 nicht versetzte, vermutete vor V. 390 den Ausfall eines weiteren Relativsatzes, e.g. $<$ Si quid relictum est, id quoque actutum mihi>.

Die Tatsache, daß eripuit auf ein solches Objekt angewiesen ist, wie es in dem quidquid-Satz in V. 388 f. vorliegt, legt den Gedanken einer Doppelfassung näher: Ein Textredaktor wollte den durch cadere und labare in V. 388 sehr prägnant ausgedrückten Verfall deutlicher herausarbeiten durch eine ausführlichere Fassung, in welcher die den Verfall bewirkenden Faktoren jeweils als Subjekt eines Verbums des Raubens erscheinen (390 und 389). In der Überlieferung gerieten diese beiden Zusatzverse freilich in falscher Reihenfolge - in den Text. Durch die enge formale Berührung mit Tro. 385 aetas Pegaseo corripiet gradu (KK 361) wird der von Habrucker bereits getilgte V. 390 ja kaum geschützt, insofern die Troerinnen auch jedem Textredaktor zur Verfügung standen. Vor allem aber zeichen sich die Verse $389 \mathrm{f}$. durch eine sich in der Wiederholung eripuit/ rapuit bekundende sprachliche und gedankliche Armut aus. 
Hinzu kommt ein logischer Fehler: Nachdem gesagt wurde, daß alles, was zuvor an Deianira begehrenswert war, vom Alter dahingerafft wurde, kann dieser Gedanke kaum so weitergeführt werden, daß „vieles von jenem” (das ja nach dem vorigen Vers vollständig vom Alter geraubt wurde) Deianiras Mutterschaft zum Opfer fiel. Sprachlich nicht besonders glücklich ist auch die Metonymie von mater in dem technischen Sinne der die Schönheit beeinträchtigenden „Mutterschaft” (viel natürlicher und weniger technisch wirkt Med. 928 Materque tota coniuge expulsa redit) und als Subjekt von rapuit, ein Sprachgebrauch, den Fitch (2004b: 241 f.) noch ausweitet, indem er die Verse $388 \mathrm{f}$. (in der überlieferten Abfolge) gestaltet in der Form et pariter (E) soror (labat codd.)/ Materque multum rapuit, so auch noch den Meleager-Mythos in die Eheproblematik zwischen Deianira und Hercules hineinziehend („meine schwesterliche Trauer und meine Mutterschaft nahmen mir meine ganze Schönheit"). Giardina suchte dagegen die bedenkliche Metonymie auch in V. $389 \mathrm{zu}$ beseitigen durch die unwahrscheinliche Änderung von Materque in Partusque.

Nach Tilgung der, wie gezeigt, in mehrfacher Hinsicht bedenklichen Verse 390/ 389 kann man die Faktoren, die dort so mangelhaft explizit werden (Altern und besonders Mutterschaft), in sprachgerechter Form in V. 388 gewinnen, wenn man hier ein wenig von Axelsons Textfassung abweicht. Überliefert ist anstatt periit labans in $\mathrm{E}$ pariter labat, in A partu labat. Axelson (KK 360) lehnt die Junktur cecidit et ... labat zurecht wegen des Tempusunterschieds ab. Mit cecidit et periit labans (labans schon Schenkl) stellt er freilich eine Wendung her, in welcher das Partizip Präsens labans (welches ja die Voraussetzung von cadere und perire bezeichnet), in störender Weise nachklappt. Stattdessen wird man sich eher an der A-Lesart orientieren und schreiben cecidit ex partu labans: „Was immer an mir einstmals begehrt war, ist jetzt schon verfallen, seit (bzw. infolge) meiner Niederkunft dahinsinkend." Auf diese Weise erhält die Temporalbestimmung olim mit ex partu ein exaktes Pendant.

Der Begriff partus wird in Vv. $407 \mathrm{f}$. aufgegriffen (NU Conciliat animos coniugum partus fere./ DE Hic ipse forsan dividet partus toros), wo Deianiras negative Bewerung des partus inhaltlich erst durch den hier rekonstruierten V. 388 verständlich wird: Der partus wirkt in diesem Fall paradoxermaßen entfremdend zwischen den Eheleuten, insofern er den Verfall der Hercules fesselnden Reize der Deianira auslöste.

Durch die Interpolation in V. 389 f. werden die in V. 388 angedeuteten Verfallsgründe (Alter und Mutterschaft) in ihrer Parallelität breit und wenig glücklich ausgeführt.

HO 719-721

... solibus virus ferum

720 Flammisque Nessus sanguinem ostendi arcuit: Hic ipse fraudes esse praemonuit dolus.

dolus als Subjekt zu praemonuit befremdet, zumal ipse nur dann prägnanten Sinn ergibt, wenn man es auf Nessus als Subjekt beziehen kann (,,der Intrigant selbst warnt vor seiner Intrige").

Heinsius' Herstellung von Hoc ... fraudis statt Hic ... fraudes nützt also nicht, zumal Hic („hier") durch Thy. 473 errat hic aliquis dolus geschützt wird. Hilfreicher wäre der Versuch von Gronovius, ferus für dolus herzustellen, der freilich die Korruptel 
(dolus E : deus A) nicht recht erklärt. Insofern Nessus als Subjekt nach dem vorausgehenden Satz ohnehin naheliegt, bedarf es einer solchen Umschreibung schwerlich. Erwünschter wäre ein das herausgearbeitete Paradox schärfendes Partizip. Aus dolus und deus gewinnt man docens: „Er selbst warnte durch seine Anweisungen, daß hier ein Betrug läge". docere im Zusammenhang der Unterweisung über das Gift hat der sterbende Nessus selbst verwendet, V. 525 Hoc docta Mycale Thessalas docuit nurus.

HO 860-862

Telum est abunde: rupe ab aetheria ferar.

Haec, haec renatum prima quae noscit diem

Oeta eligatur; corpus hinc mitti placet.

Schraders Herstellung von noscit für überliefertes poscit (verteidigt von Fitch 2004a: 206: „Mt Oeta regularly receives the sun's first rays, and hence claims them as its right") ist sicher den Alternativen pascit (Grotius), spectat (Watt) und porgit (Delz) vorzuziehen, wie schon das von Axelson (1967: 101) herbeigezogene Vorbild Tro. 10 renatum primus excipiens diem dartut, welches viel besser zu noscit paßt. Eine weitere Verbesserung ist vielleicht durch agnoscit möglich (womit sich eine exakte Entsprechung zu dem Kompositum excipiens im Vorbild ergäbe), was in der Bedeutung „wiedererkennen" noch besser zu renatum paßt und zudem die Korruptel $(g>p)$ nachvollziehbar macht. Zur Elision von quae an dieser Versstelle vgl. 766 victa quae in regno suo. Verschleifung von agnoscere begegnet häufiger an dieser Trimeterstelle, vgl. HO 1234; Med. 1021; Phaed. 1090; Ag. 923.

HO 900-902

NU Multis remissa est vita quorum error nocens,

Non dextra fuerat. fata quis damnat sua?

DE Quicumque fata iniqua sortitus fuit.

Die Unmöglichkeit der A-Variante sortitus fugit hat Zwierlein (1966: $201 \mathrm{ff}$.) dargetan. Berechtigt scheint allerdings das Verlangen nach einem bedeutungsvolleren Schluß von V. 902 als durch das Auxiliarverb fuit: Man wird ein ruit erwägen dürfen (der anonyme Rezensent der SHT erwägt furit, was weniger gut auf die zunächst im Mittelpunkt der Argumentation stehende Deianira zu passen scheint). Derjenige wird nach Deianira sein eigenes Geschick verurteilen dürfen, der eine unglückliche Bestimmung erloste und infolgedessen zu Boden gestürzt ist. Solches "Stürzen” wird im Folgenden (903 ff.) von der Amme passend durch die Wahnsinnstat des Hercules exemplifiziert, der sich selbst schließlich doch verzieh.

HO 929-931

Quicumque misero forte dissuadet mori,

930 Crudelis ille est: interim poena est mori, Sed saepe donum; pluribus venia obfuit. 
Ein derartiger Rat wird kaum „zufällig” (forte) gegeben werden. Garrod stellte mit sponte eine müßige Erweiterung zu mori her, die schon in Hinsicht auf die Wiederholung von mori in V. 930 befremdet. Heinsius wollte misera sorte, aber den Dativ wird man nicht missen wollen. Es genügt wohl, misero sorte zu schreiben; der Nominalausdruck miser sorte greift zurück auf Deianiras eigene Worte in V. 902 fata iniqua sortitus.

HO 948-958

Vacat una Danais: has ego explebo vices.

Laxate, manes; recipe me comitem tibi,

950 Phasiaca coniunx: peior haec, peior tuo

Utroque dextra est scelere, seu mater nocens

Seu dira soror es; adde me comitem tuis,

Threicia coniunx, sceleribus; natam tuam,

Althaea mater, recipe, nunc veram tui

955 Agnosce prolem - quid tamen tantum manus

Vestrae abstulerunt? claudite Elysium mihi,

Quaecumque fidae coniuges nemoris sacri

Lucos tenetis ...

Zwierlein KK 382 kommentiert Laxate, manes (was er selbst mit dem Folgenden, Fitch 2004a: 209 dagegen wieder mit dem Vorausgehenden enger verbindet) folgendermaßen: „Mit Laxate, manes wendet sich Deianira von den großen Unterweltsbüßern ab und bittet die Manen, ihr Platz zu machen". Aber durch Verg. Aen. 6.412 laxatque foros sc. Charon ist ein intransitives laxare kaum zu stützen, was nach OLD s.v. 1 b („, to make room") singulär wäre. Man wird vor V. 949 einen Versausfall diagnostizieren: Zunächst bittet Deianira die Manen, ihr den Aufenthaltsort für die schuldigen Frauen zu öffnen, dann, den Wohnort der treuen Gattinnen zu verschließen (956 ff.), e.g.

Vacat una Danais: has ego explebo vices.

$<$ Quidquid nocentes feminas claudit loci, $>$

Laxate, manes; recipe me comitem tibi,

950 Phasiaca coniunx...

HO 1245-1247

... ubi vires prius

Memet sepultae? quid patrem appello Iovem?

Quid per Tonantem vindico caelum mihi?

Fitch (2004a: 216) rechtfertigt das in V. 1246 überlieferte In me sepultae in fragwürdiger Weise durch das Thyest-Motiv in Ag. 26 f. liberis plenus tribus/ In me sepultis. Eine Vorbereitung von quid patrem appello Iovem?, wie sie Fitch in V. 1245 konjektural einführt (pater oder parens statt prius, zuvor schon patris Bothe), ist kaum erforderlich, da Hercules, wie Fitch selbst sagt, im HO ständig seinen Vater apostrophiert.

Vernünftiger Sinn ergibt sich in V. 1246 erst durch Gronovs Herstellung des komparativen Ablativs Memet (vgl. Zwierlein KK 396), welcher jetzt Fitch entgegenhält, daß die Pronominalverbindungen mit -met im $H O$ keine Parallelen haben. Diesem 
Einwand kann man begegnen, indem man (im Sinne von Gronovs Konjektur) noch überlieferungsnäher schreibt vires prius/ Iam me sepultae.

HO 1456-1466

HY Compesce diras, genitor, irarum minas;

Habet, peractum est, quas petis poenas dedit:

Sua perempta dextera mater iacet.

HE Cecidit dolose: manibus irati Herculis

1460 Occidere meruit; perdidit comitem Lichas.

Saevire in ipsum corpus exanime impetus

Atque ira cogit. cur minis nostris caret

Ipsum cadaver? Pabulum accipiant ferae.

HY Plus misera laeso doluit, hinc aliquid quoque

1465 Detrahere velles: occidit dextra sua,

Tuo dolore; plura quam poscis tulit.

Am Anfang von V. 1459 favorisiert Zwierlein KK 408 f. Richters Cecidit dolose (Ceci dolores A, Recte dolor es E). Cecidit ist als Wiederaufnahme von iacet nicht zu bezweifeln, aber die Bewertung von Deianiras Selbstmord als "heimtückisch” (weil sie sich so einer Bestrafung durch Hercules selbst entzog) erscheint zumindest nicht zwingend (Richters dolose, welches bereits von Axelson [1967: 77] gutgeheißen wurde, wird variiert von Delz mit Clepsit dolo se und von Giardina mit Fecit dolose; dagegen wendet sich Fitch [2004b: 246] gegen dolose und läßt Hercules dem Hyllus in wenig überzeugender Weise entgegenhalten Caecus dolore es). Hercules muß den Selbstmord seiner Frau kaum derart bewerten, er kann einfach konstatieren, daß sie aus Schmerz Selbstmord begangen hat und sich so der verdienten Tötung durch seine Hand entzogen hat.

Dann wird man ein überlieferungsnäheres Cecidit dolore herstellen (das Wort dolor entnimmt auch Averna der Überlieferung, die Hercules in wenig idiomatischer Form konzedieren läßt Recte dolor es $<t>$, $<$ sed $>$ manibus irati Herculis/ ...) und als Folie für manibus irati Herculis/ Occidere meruit verstehen. Ein wichtiges Argument zugunsten dieser Textgestaltung dürfte darin liegen, daß die Antithese dolore (sc. suo) - manibus ... Herculis später in den Worten des Hyllus mit occidit dextra sua, / Tuo dolore (1465 f.) in umgekehrter Form aufgegriffen wird.

HO 1518-1527

O decus mundi, radiate Titan,

Cuius ad primos Hecate vapores

1520 Lassa nocturnae levat ora bigae:

Dic sub Aurora positis Sabaeis,

Dic sub occasu positis Hiberis,

Quique ferventi quatiuntur axe,

Quique sub plaustro patiuntur ursae,

1525 Dic ad aeternos properare manes

Herculem et regnum canis inquieti,

Unde non umquam remeabit ille. 
Die Korruptelen in der Überlieferung von V. 1527 (umquam A : numquam E; remeabit Leo : remeavit codd.; ille Schenkl : inde $\mathrm{E}$ : ullus A) machen mißtrauisch. Sehr ähnlich hinsichtlich der äolischen Metrifizierung ist Cat. 3.12 unde negant redire quemquam (wenn das mutmaßliche Vorbild der Formulierung sich tatsächlich auf den Unterweltsgang des Odysseus bezieht, so liegt hier möglicherweise sogar eine sehr bewußte Intertextualität vor, die den bei Catull auf den Sperling angewandten Ausdruck wieder in die Heroenwelt zurückträgt, vgl. Gärtner 2006). Die catullische Versklausel redire quemquam macht - wie schon Carlsson beobachtete - sehr zweifelhaft, daß die A-Variante ullus auf bloßer Korruptel beruhen sollte (im Gegenteil ist die E-Variante inde viel eher eines Influenzfehlers aus Unde verdächtig); somit werden auch die ullus ebenfalls beseitigenden Versuche von Watt (Unde non umquam remeabit in te) und Delz (Unde non retro remeabit umquam) fragwürdig (Fitch, Annaena p. 222 f. plädiert dagegen wieder für ille am Versende). Insofern die enge syntaktische Parallelität zweier aufeinanderfolgender Versen eine Stileigentümlichkeit des vorliegenden Chorlieds ist, liegt es nahe, die Überlieferung durch eine haplographische Zusammenziehung zweier Parallelverse zu erklären:

Dic ad aeternos properare manes

Herculem et regnum canis inquieti,

Unde non umquam remeavit ullus,

Unde iam numquam remeabit ille.

In dieser Textfassung dürfte klar sein, daß sich non ... ullus im Sinne des Topos auf die Sterblichen vor Hercules (ille) beziehen muß, daß sich also der von Axelson (1967: $37 \mathrm{f}$.) erhobene inhaltliche Einwand (Hercules ist tatsächlich einmal zurückgekehrt) gegen ullus erledigt (der zurecht bestünde, wenn es bei Unde non umquam remeavit ullus bliebe): Der Fall des Hercules wird in einem parallel gestalteten eigenen Vers dem Geschick der restlichen Menschheit gegenübergestellt.

HO 1607-1617

CH Effare casus, iuvenis, Herculeos precor

Voltuve quonam tulerit Alcides necem.

PH Quo nemo vitam. CH laetus adeone ultimos

1610 Invasit ignes? PH esse iam flammas nihil

Ostendit ille. quid sub hoc mundo Hercules

Immune vinci liquit? en domita omnia.

$\mathrm{CH}$ Inter vapores quis fuit forti locus?

$P H$ Quod unum in orbe vicerat nondum malum,

1615 Et flamma victa est; haec quoque accessit feris:

Inter labores ignis Herculeos abit.

CH Edissere agedum, flamma quo victa est modo?

Die Frage des Chors in V. 1613 unterbricht Philoctets Deklamation über die Besiegung der Flammen durch Hercules, ohne diese Ausführungen irgendwie zu beeinflussen (Quod unum in orbe vicerat nondum malum knüpft exakt bei en domita omnia an). Richters radikale Tilgung der Vv. 1613-1616 kommt schon deshalb nicht in Betracht, weil 
diese „Deklamation” auf die glänzende Schlußsentenz in V. 1616 (gestaltet nach Herc. 1316 Eat ad labores hic quoque Herculeos labor) zuläuft.

Man wird V. 1613, der in seiner überlieferten Stellung unerträglich ist, eher hinter V. 1617 versetzen als tilgen. Die präzisierende Doppelung der Frage hat eine exakte Parallele in Vv. 1607 f. Wie dort casus ... Herculeos modifiziert wird durch tulerit Alcides necem, so hier flamma quo victa est modo durch das gesuchtere Inter vapores (Inter labores trivialisierend Herrmann, ohne Versetzung). In beiden Fällen fokussiert die zweite, präzisere Frage auf Hercules' Heldentum (Voltuve quonam bzw. forti).

Oct. $45-50$

... cuius extinctus iacet

Frater venenis, maeret infelix soror

Eademque coniunx nec graves luctus valet

Ira coacta tegere crudelis viri,

Quem spreta refugit semper atque odio pari

50 Ardens mariti mutua flagrat face.

Animum dolentis nostra solatur fides

Pietasque frustra: vincit immitis dolor

Consilia nostra nec regi mentis potest

Generosus ardor, sed malis vires capit.

Die Argumentation von Zwierlein KK 450 ff., Ira coacta ... crudelis viri müsse sich auf die Tatsache beziehen, daß Nero der Octavia verbot, ihre Angehörigen zu betrauern, wird durch folgende Umstände widerlegt: 1. Die folgenden Verse 51-54 stellen gerade die Unbezwingbarkeit von Octavias (nicht von Neros) Affekten heraus, und 2. V. 176 Dolor ira maeror miseriae luctus dabunt sc. vires zeigt, daß sich die Affekte ira und luctus sehr wohl in der Person Octavias vereinigen. Als Folgerung ergibt sich, daß Ira wie luctus auf Octavia zu beziehen, das Partizip coacta einfach das übergeordnete Prädikat nec ... valet/ ... tegere begründet, crudelis viri mit dem Folgenden zu verbinden und nach tegere stark zu interpungieren ist, ferner daß die von Zwierlein gewählte Textgestalt am Anfang von V. 49 (Quem spreta Bährens) nicht richtig sein kann.

Überliefert ist in A Quem secreta (unmetrisch), in den übrigen Handschriften Secreta. Ferri akzeptiert die metrisch mögliche Lesart crudelis viri/ Secreta refugit semper (freilich ist die Interpolation von Quem schwer zu erklären; Liberman konstituiert eine Lücke: Quem $<\ldots . .>/$ Secreta ...) und deutet "she flees any occasion of meeting the cruel man in private". Abgesehen davon, daß sich hiermit ein allzu schwacher Sinn ergibt (die Feindschaft zwischen Octavia Nero geht über die Vermeidung gemeinsamer Intimität weit hinaus), muß dem folgenden Partizipialausdruck odio paril Ardens mariti, sofern dieser richtig überliefert ist, ein Ausdruck der Feindseligkeit des Nero gegenüber Octavia vorausgegangen sein (so richtig Zwierlein). Insofern hilft auch Fitchs (2004a: $234 \mathrm{f}$.) Herstellung von Secreta repetit "she always hurries back into seclusion" (der crudelis viri mit Ira wie Zwierlein verbindet) nicht weiter. Die Korruptel muß in secreta liegen.

Bothe schlug scelera für secreta vor, womit nicht nur das Metrum geheilt wird, sondern auch ein passender Begriff eingesetzt wird: Claudius wurde durch das scelus seiner Gattin beseitigt (44), diese wiederum durch das scelus ihres Sohnes Nero (45); 
Octavia hat ständig ihrerseits vor verbrecherischen Anschlägen Neros zu flüchten (49), entbrennt infolgedessen in gleichem Haß auf ihren Ehemann (49 f.) und läßt den Chor in Anbetracht der Unbezwingbarkeit ihrer Affekte (51-54) ein nefandum .../ Scelus (55 f.) ihrerseits fürchten (dieses scelus kann sich nach der vorausgegangenen Beschreibung von Octavias unbeherrschbaren Affekten nicht auf der Seite Neros liegen). Zur Furcht des Chors bezüglich einer Heroine, die ihre Affekte nicht beherrschen kann, ist Med. 866 ff. zu vergleichen Frenare nescit iras/Medea, non amores;/ Nunc ira amorque causam/ Innxere: quid sequetur?. Ebenso muß auch hier der Chor vage ein furchtbares scelus als Folge der unbeherrschbaren ira der Octavia fürchten.

Bothe schrieb am Anfang von V. 48 Quae scelera (als Ausruf); ein noch prägnanterer chiastischer Ausdruck ergäbe sich mit crudelis viril Quot scelera refugit semper (semper korrespondierend mit Quot).

Oct. $100 \mathrm{f}$.

Toleranda quamvis patiar, haud umquam queant

Nisi morte tristi nostra finiri mala.

Zwierlein KK 452 f. präferiert Badens Deutung „aerumnas mihi tolerandas quamvis patienter feram" zurecht derjenigen von Leo („quamvis quae patior ferri possint"): Der Gedanke einer Erträglichkeit der Leiden ist unvereinbar mit $57 \mathrm{f}$. O mea nullis aequanda malis/ Fortuna. Ferri entscheidet sich dagegen wieder für Leos Interpretation.

Wie Zwierlein zeigt, erfordert Badens Deutung eine nicht ganz leichte prägnante Auffassung von pati in dem Sinne „mit Geduld ertragen”. Dieser Sinn läßt sich mit einer sehr leichten Änderung (die nicht wie die meisten früheren Versuche bei quamvis ansetzen wird: quaevis Lipsius; iam vix Baehrens - aber der Gedanke „wie sehr ich mich auch um Duldsamkeit bemühe" erscheint intakt) explizit in den Text legen, die zugleich dem Ausdruck Nisi morte tristi sein ablativisches Pendant gibt:

Tolerando quamvis patiar, haud umquam queant

Nisi morte tristi nostra finiri mala.

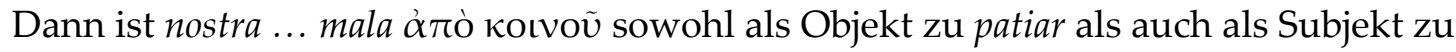
queant/ ... finiri zu ziehen. Zur Kurzmessung der Endsilbe des ablativischen Gerundiums an dieser Versstelle vgl. Tro. 264; Phoen. 558; HO 1862. Der Ausdruck entspricht tendenziell und strukturell auch der Aufforderung der Amme in 177 Vince obsequendo. Als Vorbild kommt vor allem die bei Zwierlein zitierte Vergilstelle Aen. 5.710 Quidquid erit, superanda omnis fortuna ferendo in Frage (hiernach Sil. Pun. 6.375 f. nec tam fugisse cavendo/ Adversa egregium quam perdomuisse ferendo).

Oct. $498-502$

... Brutus in caedem ducis,

A quo salutem tulerat, armavit manus:

500 Invictus acie, gentium domitor, Iovi

Aequatus altos saepe per honorum gradus

Caesar nefando civium scelere occidit. 
Die vorgebrachten Verteidigungen weder für altos noch für saepe vermögen zu überzeugen: altos wäre nach Ferri z.St. erforderlich, da nicht von republikanischen Ämtern im eigentlichen Sinne die Rede sei („not Republican magistracies, but the exceptional privileges awarded to Caesar in his last years"). Aber die Pointe des Ausdrucks dürfte gerade darin liegen, daß Caesar (im Vergleich zu den späteren, echten Principes) seine göttergleiche Stellung letztlich durch den Aufstieg durch (per) republikanische Ehrenämter erlangt hat.

$\mathrm{Zu}$ saepe vermerkt Ferri „because the status of equal to the gods would suggest permanence” (etwas anders Zwierlein KK 469 „,nicht erst am Ende war er Jupiter auf Erden"), aber eine solche Modifikation dürfte die Gleichstellung eines Menschen mit dem höchsten Gott nur schwächen (zumal saepe immer ein non semper impliziert), und im Anschluß an die Titel Invictus acie und gentium domitor erwartet man in der Tat eine permanente Eigenschaft. Fitch (2004a: 247) will dagegen saepe in der Verbindung altos saepe per honorum gradus gemäß V. 721 adnominal verstehen; doch ein so gedeutetes saepe gerät in Widerspruch zu dem durch per angedeuteten Gedanken eines cursus honorum, der es gerade nicht erfordert, daß man die einzelnen Ehrenämter vielfach durchläuft.

Heinsius' Konjektur paene für saepe (aufgenommen bei Liberman) schwächt den Ausdruck ebenfalls, und Büchelers ipse ist, wie Zwierlein dartut, problematisch, weil Caesar in ducis (V. 498) bereits im vorigen Exempel praesent war. Damsté will mit alios usque den Titel Iovil Aequatus als höchste Steigerung anderer sukzessiver Ehrungen herausstellen (wohl etwas zu technisch gedacht). Zwierlein erwägt wie Peiper passend ein zu Iovi gehöriges alto[s]. Man wird beide Probleme durch einen möglichst sparsamen Eingriff angehen und unter Annahme eines Wortabtrennungsfehlers altos saepe in alto nempe ändern. Der Untergang Caesars bildet für Neros zynische „Vorsichtsmaßnahmen” gewissermaßen ein argumentum a maiore ad minus: Zur Vorsicht mahnt gerade die Tatsache, daß Caesar, der auf dem Weg über die republikanische Ämterlaufbahn doch wohl eine jupitergleiche Stellung erlangt hat, d.h. derjenige Mensch, der es auf Erden doch wohl am weitesten gebracht hat, schließlich trotzdem ermordet wurde. In diesem Zusammenhang forciert nempe in passender Weise die Bedeutung des Exempels Caesar. Die Qualifikation Iovil Aequatus alto ... per honorum gradus ist im Vergleich zu den vorausgegangenen Invictus acie und gentium domitor nicht aus sich selbst heraus evident.

Oct. 636-643

Utinam, antequam te parvulum in lucem edidi

Aluique, saevae nostra lacerassent ferae

Viscera: sine ullo scelere, sine sensu innocens

Meus occidisses; iunctus atque haerens mihi

640 Semper quieta cerneres sede inferum

Proavos patremque, nominis magni viros,

Quos nunc pudor luctusque perpetuus manet

Ex te, nefande, meque quae talem tuli. 
Allgemein akzeptiert wird die in den codd. recc. antizipierte Änderung von quietam ... sedem (A) in quieta ... sede durch Heinsius, die erst eine grammatische Konstruktion des Satzes ermöglicht.

Jedoch scheinen die Ausdrücke Meus occidisses und iunctus atque haerens mihi eher auf eine abgeschiedene Zweisamkeit von Mutter und Sohn in der Unterwelt hinauszulaufen als auf ein Treffen mit den männlichen Vorfahren Neros. Überhaupt scheint der in cerneres implizierte topische Gedanken des „Wiedersehens” eines Gestorbenen mit seinen Vorahnen (vgl. Ferri z.St.) fragwürdig in bezug auf ein Kind, welches das Licht der Welt niemals erblickt hat und somit von seinen männlichen Ahnen nichts weiß.

Man wird eher den in V. 640 überlieferten Akkusativ quietam ... sedem beibehalten (die Junktur sedem cernere von dauerndem Aufenthalt wie bei Luc. Phars. 7.23 vetito patrias ultra tibi cernere sedes) und nach diesem Vers eine Lücke annehmen, in welcher einige Worte ausgefallen sind, die den Kontakt des mit seiner Mutter in der quieta sedes befindlichen Kindes mit der politischen Welt seiner männlichen Vorfahren in negierter Form beschreiben, e.g.

... iunctus atque haerens mihi

640 Semper quietam cerneres sedem inferum

$<$ Nec gloriosos scelere pollueres tuo $>$

Proavos patremque, nominis magni viros,

Quos nunc pudor luctusque perpetuus manet

Ex te, nefande, meque quae talem tuli.

Oct. $717-723$

... nec diu placida frui

Quiete licuit. visa nam thalamos meos

Celebrare turba est maesta: resolutis comis

720 Matres Latinae flebiles planctus dabant;

Inter tubarum saepe terribilem sonum

Sparsam cruore coniugis genetrix mei

Vultu minaci saeva quatiebat facem.

Die syntaktische Beziehung von V. 721 auf die folgende Periode (die Heinsius durch seine [bei Liberman aufgenommene] Konjektur Inter tubarum saepta terribili sonitu [Inter ... saepta Tmesis] zementiert) ist irrig. Daß man resolutis comis/ Matres Latinae flebiles planctus dabant/ Inter tubarum saepe terribilem sonum zu verbinden hat, zeigt (wie immer man sich die genaue Beziehung zwischen der Octavia und dem Bericht des Tacitus zurechtlegt) die im Zusammenhang des Todes der Agrippina stehende Parallele Tac. ann. 14.10 et erant qui crederent sonitum tubae collibus circum editis planctusque tumulo (<e> tumulo Orelli : [tumulo] Koestermann coll. 9, 1) matris audiri. 


\author{
Quid cui licuit regnum caeli \\ Sperare, parens tanta Neronis? \\ Non funesta violata manu \\ 955 Remigis ante, \\ Mox et ferro lacerata diu \\ Saevi iacuit victima nati?
}

Es erscheint fraglich, ob die Periode in Vv. 954-957 zurecht als rhetorische Frage interpungiert wird. Zwar erhielt Agrippina bei dem geplanten Schiffbruch gemäß Tac. ann . 14.5 tatsächlich eine einzige Wunde an der Schulter, doch wird andererseits in dem früheren Chorlied (Vv. 350 ff. - wo von der Wunde bezeichnenderweise nichts gesagt ist) hervorgehoben, wie die am Schiffbruch Beteiligten sich in paradoxer Weise selbst unter eigener Todesgefahr um die Rettung Agrippinas bemühten.

Daher dürfte die genannte Periode eher als Aussage zu fassen sein gemäß dem topischen Gedanken „dem Schiffbruch entkommen, aber dann in der vermeintlichen Sicherheit umgekommen” (vgl. etwa Verg. Aen. 6.358 ff.). Mit leichter Änderung liest man dann am Anfang von V. 956 Mox <s>ed (ante und mox sind durch die Wortstellung nachdrucksvoll konfrontiert).

Ferner muß man zweifeln, ob multis vulneribus bei Tac. ann. 14.8 das sonderbare lacerata diu, welches die Grausamkeit so eigenartig durch die Zeitdauer umschreibt, rechtfertigt. Insofern Agrippina (die gemäß Tacitus im Bett getötet wurde) in 606-608 sagt

Perempta ferro, foeda vulneribus sacros

Intra penates spiritum effudi gravem

Erepta pelago ...,

liegt es sehr nahe, hier dieselbe pathetische Antithese zu forcieren durch folgende Textgestaltung:

Non funesta violata manu

955 Remigis ante,

Mox $<$ s $>$ ed ferro lacerata domi

Saevi iacuit victima nati.

Erst vor dem Hintergrund der negierten Aussage in Vv. 954 f. erhält die Schilderung der erneuten Untat Neros in Vv. 956 f. die wünschenswerte Schärfe.

Oct. $963-968$

Testor superos - quid agis, demens?

Parce precari quis invisa es

Numina divum: Tartara testor

Erebique deas scelerum ultrices

Et te, genitor

Dignum tali morte et poena:

Non invisa est mors ista mihi. 
Nach dem überlieferten Text würde sich Octavia in V. 967 in sehr überraschender Weise über den Tod ihres sonst heißgeliebten Vaters äußern (Liberman ändert die Richtung dieser Aussage durch Herstellung von Nec te .../ Dignum tali morte et poena).

Leo versuchte, V. 967 auf den Tod des Nero zu beziehen, indem er vor diesem Vers den Ausfall von <perde tyrannum> annahm; sein Vorschlag wurde modifiziert von Courtney, der zurecht darauf besteht, daß auf testor eine Aussage folgen muß (<facibus saevis/ Qui regem ipsum mox agitabis>). Letztlich ebenfalls auf Leos Ansatz beruht der Versuch von Fitch (2004a: 260 f.), eine längere nach V. 967 anzusetzen (Dignum tali morte et poenal <Esse tyrannum, qui me extinxit/ ...>).

Kaum in Betracht kommt die Erwägung von Ferri, durch die Änderung in genitrix,/ Dignam eine Apostrophe an Agrippina zu gewinnen (gemäß Tac. ann. 14.64), welche Octavia kaum wie ihre leibliche Mutter in V. 10 als genitrix bezeichnen würde.

Dagegen wollen Axelson und Zwierlein KK 477 f. den V. 967 auf Octavia selbst beziehen: Axelson konstruiert einen von genitor abhängigen Genitiv in der Form Tali indignae morte et poena, wohingegen Zwierlein an testor prädikativ anknüpft mit Digna haut tali morte et poena. Der anonyme Rezensent der SHT modifiziert diesen Vorschlag zu Dignae haut tali morte et poena, wobei Dignae als Dativ mit mihi im folgenden Vers verbunden werden soll.

Ein durchschlagendes Argument für die letztgenannte Lösungsrichtung liefert wohl V. 968, wo die auf Octavias Tod gehende Wendung mors ista äußerst hart anschließt, wenn unmittelbar zuvor vom Tod einer anderen Person die Rede gewesen ist. Überdies weist auch die von Junge (1999: 251) nachgewiesene Parallele Med. $256 \mathrm{f}$. quippe quem poenae expetit/ Letoque Acastus in die Richtung, daß das Hendiadyoin morte et poena auf die der Octavia drohende Hinrichtung zu beziehen ist. Ich vermute eine zweigliedrige Aussage der Octavia über ihren eigenen Tod, deren erster Teil ein unpersönliches dignum est enthalten hat, e.g.:

Testor superos - quid agis, demens?

Parce precari quis invisa es

Numina divum: Tartara testor

Erebique deas scelerum ultrices

Et te, genitor:

$<$ Abrumpere me non est vitam>

Dignum tali morte et poena;

Non invisa est mors ipsa mihi.

Dann beteuert Octavia gegenüber der Unterwelt, den Furien und ihrem Vater, daß sie die Art ihrer Hinrichtung durch Nero unwürdig findet (worin eine Anklage an die Furien impliziert ist), aber den Tod als solchen nicht ablehnt (und somit keine Scheu vor der Unterwelt als solcher oder ihrem dort befindlichen Vater empfindet). Damit ergibt sich geradezu ein Kommentar zu den gelegentlich als widersprüchlich empfundenen Aussagen Octavias in einem früheren Chorlied (653 f. Dabit hic nostris finem curis/ Vel morte dies; $659 \mathrm{f}$. Absint tantum tristes poenael Letique metus). In die gleiche Richtung geht auch 106-108 Trepidante semper corde non mortis metu,/ Sed sceleris - absit crimen a fatis meis,/ Mori iuvabit.

Heinsius will, um die Wiederholung des Begriffs mors zu vermeiden, entweder in V. 967 morte in sorte oder in V. 968 mors in sors ändern: Ersteres verbietet sich, weil poena einen ausdrucksstarken Partner in der hendiadyoin-artigen Verbindung benötigt, 
letzteres (akzeptiert von Liberman) führt zu einer sinnwidrigen Aussage, insofern Octavia, wenn ista sors auf morte et poena zurückgreift, bekundet, der unwürdige „Tod unter Qualen" sei ihr nicht verhaßt. Um einen entsprechenden Widerspruch in der Überlieferung (morte - mors ista) zu vermeiden und ein sinnvolle Antithese zu morte et poena zu gewinnen, ist oben mors ipsa (zur Junktur vgl. Tro. 397) gesetzt worden.

Prof. Dr. Thomas Gärtner

Institut für Altertumskunde

Universität zu Köln

E-mail: th-gaertner@gmx.de 


\section{Literaturverzeichnis}

Axelson, Bertil (1967) Korruptelenkult: Studien zur Textkritik der unechten Seneca-Tragödie Hercules Oetaeus. (Scripta minora Regiae Societatis Humaniorum Litterarum Lundensis; 1964/65.3.) Lund: Gleerup.

Billerbeck, Margarethe; Somazzi, Mario (2009) Repertorium der Konjekturen in den SenecaTragödien. (Mnememosyne: Supplementa; 316.) Leiden: Brill.

Fitch, John G. (2004a) Annaeana tragica: notes on the text of Seneca's tragedies. (Mnemosyne: Supplementa; 256.) Leiden: Brill.

Fitch, John G. (2004b) ,Textual Notes on „Hercules Oetaeus” and on Seneca's „Agamemnon” and „Thyestes".' - CQ 54.1, 240-254.

Gärtner, Thomas (2006) ,Cat. carm. 3,11s. - Eine Anspielung auf Philitas von Kos?' Göttinger Forum für Altertumswissenschaft 9, 13-20.

Giardina, Giancarlo (ed.) (2007) Lucio Anneo Seneca, Tragedie. 1: Ercole, Le Troiane, Le Fenicie, Medea, Fedra. Pisa; Roma: Serra.

Giardina, Giancarlo (ed.) (2009) Lucio Anneo Seneca, Tragedie. 2: Edipo, Agamennone, Tieste. Pisa; Roma: Serra.

Jakobi, Rainer (1988) Der Einfluß Ovids auf den Tragiker Seneca. (Untersuchungen zur antiken Literatur und Geschichte; 28.) Berlin; New York: de Gruyter.

Junge, Rebekka (1999) Nicholas Trevet und die Octavia Praetexta: Editio princeps des mittelalterlichen Kommentars und Untersuchungen zum pseudosenecanischen Drama. Paderborn etc: Schöningh.

Strzelecki, Ladislaus (= Władysław) (1938) De Senecae trimetro iambico quaestiones selectae. Kraków: Nakł. Polskiej Akad. Umiejetności.

Zwierlein, Otto (1966) Die Rezitationsdramen Senecas: mit einem kritisch-exegetischen Anhang. (Beiträge zur klassischen Philologie; 20.) Meisenheim am Glan: Hain.

Zwierlein, Otto (1986) Kritischer Kommentar zu den Tragödien Senecas. Stuttgart: Steiner-Verlag-Wiesbaden.

Zwierlein, Otto (2004) Lucubrationes Philologae. Bd. I: Seneca. (Untersuchungen zur antiken Literatur und Geschichte; 71.) Berlin: de Gruyter.

Zwierlein, Otto (ed.) (2009) L. Annaei Senecae Tragoediae, incertorum auctorum Hercules (Oetaeus), Octavia. Oxonii: Clarendon. (1. Ausg. 1986.) 